11

\title{
Влияние лигандов и растворителя на безызлучательные переходы в полупроводниковых квантовых точках (06зор)
}

\author{
(C) В.Л. Ермолаев
}

Университет ИТМО, 197101 Санкт-Петербург, Россия

e-mail: ermolaev@oi.ifmo.ru

Поступила в редакцию 03.04.2018 г.

Собраны данные о квантовых выходах и временах затухания фотолюминесценции (PL) квантовых точек. Проведено сопоставление фотопроцессов, осуществляющихся в квантовых точках, с фотопроцессами, происходящими в сложных органических молекулах в конденсированной фазе. Обзор состоит из введения, трех частей и выводов. Первые две части посвящены квантовым точкам, построенным из непрямозонных полупроводников. Первая часть посвящена данным о выходах и временах затухания PL углеродных квантовых точек, а в табл. 1 приведены выборочные значения и даны краткие комментарии к этим данным. В табл. 2 той же части собраны данные о процессах быстрой релаксации в тех же объектах. Во второй части табл. 3 и 4 и последующий текст содержат аналогичную информацию о кремниевых квантовых точках. Данные о фотопроцессах в квантовых точках, построенных из прямозонных полупроводников, собраны в третьей части. Данные о выходах PL, временах затухания и процессах релаксации собраны в табл. 5 и 6. Особое внимание в обзоре уделено влиянию изменения частоты колебаний в окружении квантовой точки на выходы PL и скорости процессов релаксации между электронными уровнями внутри зон, что указывает на применимость индуктивно-резонансного механизма безызлучательных переходов к этим системам.

DOI: $10.21883 /$ OS.2018.08.46368.97-18

\section{Введение}

В последнюю четверть века появилось громадное количество научных статей, посвященных исследованию фотоники полупроводниковых квантовых точек и перспективам их различных практических применений. Первоначально основное внимание исследователей привлекали квантовые точки из прямозонных полупроводников типа CdSe, CdTe, HgTe, PbS, PbSe, InAs и др. [1-6]. Однако в последние десятилетия все больше внимания стали уделять изучению квантовых точек из непрямозонных полупроводников: $\mathrm{C}, \mathrm{Si}$ и $\mathrm{Ge}$ [7-9]. Вызвано это двумя причинами: токсичностью и дороговизной большинства элементов, входящих в состав прямозонных полупроводников, и дешевизной и распространенностью углерода и кремния в земной коре. Кроме того, малая токсичность у углеродных и кремниевых квантовых точек открывает широкие возможности для использования их в биологии и медицине.

В настоящем обзоре собраны данные о выходах и временах жизни фотолюминесценции (PL) различных типов квантовых точек и сопоставлены механизмы процессов излучения и безызлучательных переходов в них с давно и подробно изученными процессами люминесценции в сложных органических молекулах в конденсированной фазе [10-20]. В частности, отмечена роль в тушении PL квантовых точек индуктивно-резонансного механизма безызлучательных переходов, т. е. фёрстеровского переноса энергии от электронно-возбужденных состояний в квантовых точках на колебания ядра, лигандов и (или) окружающих точки молекул растворителя.

Обзор состоит из введения и трех частей. В первой и второй частях собраны и обсуждены имеющиеся данные о выходах и длительности PL в квантовых точках, построенных из углерода и кремния, являющихся непрямозонными полупроводниками. В третьей части приведены выходы и длительность люминесценции квантовых точек, состоящих из прямозонных полупроводников. При этом акцент сделан на работах, посвященных изучению влияния лигандов и окружения на безызлучательные переходы в прямозонных полупроводниковых точках. Следует отметить, что относительно структуры электронных уровней, механизмах излучательных и безызлучательных переходов в полупроводниковых квантовых точках в настоящее время полной ясности нет.

Представляет интерес сопоставить фотофизические свойства этого нового класса люминофоров со свойствами ранее подробно изученных сложных органических молекул. Известно, что люминесцентные свойства сложных органических молекул в конденсированной фазе хорошо описываются схемой трех уровней ЯблонскогоТеренина-Льюиса: основного синглетного $\left(S_{0}\right)$, первого возбужденного синглетного флуоресцентного $\left(S_{1}\right)$ и метастабильного триплетного $\left(T_{1}\right)$ уровней; переход между уровнями $T_{1}$ и $S_{1}$ запрещен спиновыми правилами отбора. Имеется также система высоких возбужденных синглетных $\left(S_{n}, n>1\right)$ и триплетных $\left(T_{n}, n>1\right)$ уровней, при возбуждении на которые молекула быстро (за сотни или десятки фемтосекунд) безызлучательно переходит 
на флуоресцентное $S_{1}$ (для $S_{n}, n>1$ ) или триплетное $T_{1}$ (для $T_{n}, n>1$ ) состояние (закон Вавилова [21], правило Каша [22]. Сходная (хотя и более сложная) схема электронных уровней предлагается для объяснения процессов PL в различных квантовых точках.

При рассмотрении фотопроцессов, происходящих в квантовых точках различного состава, напрашивается сходство с такими процессами в сложных органических молекулах в конденсированной фазе. Например, для ряда квантовых точек, состоящих из легких элементов (углерод, азот, кислород, водород, кремний) можно провести параллель с ароматическими соединениями, состоящими из аналогичных атомов. Как и в ароматических соединениях, в углеродных и кремниевых квантовых точках доказано [23-26] наличие синглетного и триплетного уровней (аналог схемы Яблонского-Теренина-Льюиса), с которых происходят излучательные и безызлучательные переходы в основное состояние. Из-за запрета на интеркомбинационные переходы вероятность перехода с триплетного уровня на основной синглетный для сложных органических молекул в $10^{8}-10^{3}$ раз меньше вероятности перехода с возбужденного синглетного уровня. Аналогичная ситуация в окисленных кремниевых квантовых точках, правда, различие вероятностей перехода составляет порядок для квантовых точек размером $9.0 \mathrm{~nm}$, два порядка для $4.2 \mathrm{~nm}$ и до трех порядков для точек меньшего размера. Расщепление между нижними возбужденными синглетным и триплетным уровнями в квантовых точках существенно меньше, чем в ароматических молекулах, и составляет по данным [23] от $30 \mathrm{meV}$ для кремниевых квантовых точек, излучающих в области $2.25 \mathrm{eV}$, до $\sim 2 \mathrm{meV}$ для излучающих около $1.2 \mathrm{eV}$.

Имеются и определенные отличия между квантовыми точками, с одной стороны, и сложными молекулами, комплексами лантанидов или переходных металлов, с другой. Если при исследовании молекул или комплексов металлов мы имеем дело, как правило, с центрами одного химического состава, то в случае квантовых точек в большинстве случаев - с их набором, в котором точки отличаются количеством входящих в нее атомов, а также различием и количеством взаимодействующих с поверхностью молекул. Это приводит к значительному уширению их спектров PL и поглощения. В то же время, если состав квантовой точки из прямозонных полупроводников однороден, то спектральная ширина его полосы люминесценции достаточно узкая. Кроме того, в углеродных и кремниевых квантовых точках в процессах люминесценции существенную роль играют поверхностные электронные уровни ловушки, как правило связанные с лигандами, взаимодействующими с поверхностью квантовых точек. После поглощения квантовой точкой фотона и релаксации возникший экситон, мигрируя по квантовой точке, захватывается ловушкой, и излучение или дезактивация осуществляется с ее уровня. Схема уровней для углеродных и кремниевых квантовых точек изображена на рис. 1.

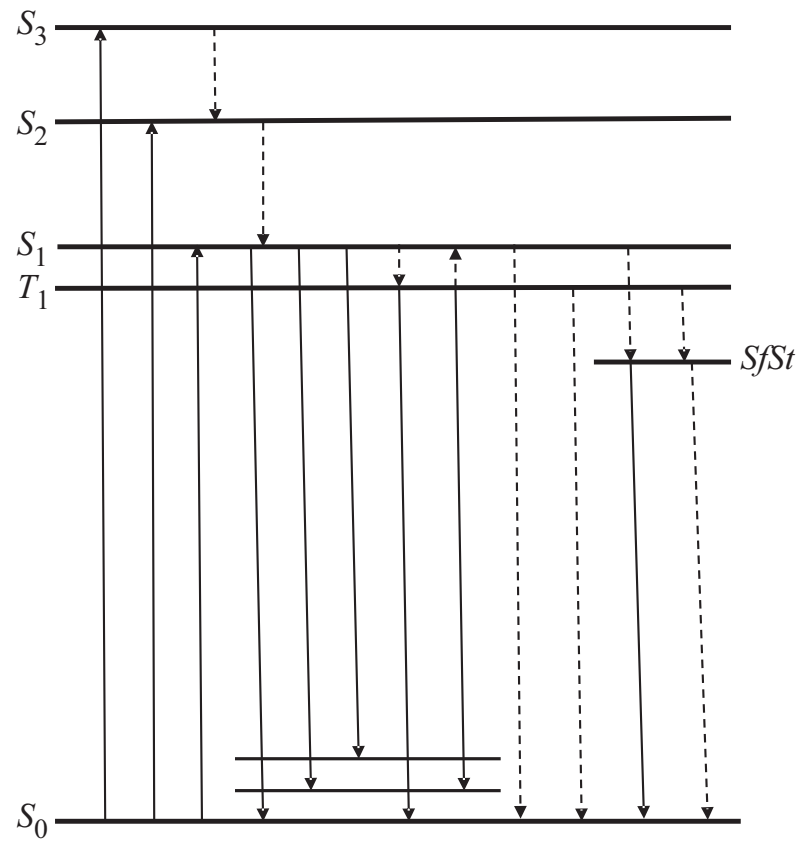

Рис. 1. Схема энергетических уровней и переходов между ними в квантовых точках, построенных из непрямозонных полупроводников. Жирные горизонтальные уровни - электронные уровни: синглетные $S_{n}$, триплетные $T_{1}$ и поверхностный уровень $S f S t$, более тонкие горизонтальные линии - электронноколебательные состояния. Сплошные вертикальные линии излучательные переходы, штриховые - безызлучательные. Схема уровней построена по аналогии со схемой уровней сложных органических молекул в конденсированной фазе и, по нашему мнению, достаточно хорошо описывает фотопроцессы в непрямозонных полупроводниках.

\section{Углеродные квантовые точки}

PL-свойствам углеродных квантовых точек (CQD) последнее время в научной литературе уделяется очень большое внимание. Это обусловлено рядом их преимуществ перед использующимися до этого квантовыми точками из прямозонных полупроводников, в составе которых присутствуют токсичные тяжелые элементы. Кроме того, исследователей привлекает дешевизна и разнообразие органических веществ, из которых синтезируются CQD, и в ряде случаев простота самих методов изготовления. Во многих случаях их PL-свойства также хорошо сохраняются в течение длительного времени и под воздействием интенсивного облучения. Большинство исследованных CQD точек люминесцируют в голубой или зеленой областях спектра, хотя в ряде работ спектры PL удалось продвинуть в красную и близкую ИК область (табл. 1).

Первые синтезированные CQD не люминесцировали или обладали очень слабой PL. Сан и соавторы [27] впервые показали, что если пассивировать их поверхность полиэтиленгликолем, замещенным на концах аминами, то можно получить достаточно высокий квантовый 
Таблица 1. Квантовые выходы и времена затухания люминесценции CQD

\begin{tabular}{|c|c|c|c|c|c|c|}
\hline $\begin{array}{l}\text { Квантовая точка, } \\
\text { лиганд, радиус, nm }\end{array}$ & Растворитель & $\begin{array}{l}\text { Частота макс. } \\
\text { PL, } \mathrm{cm}^{-1}\end{array}$ & $\begin{array}{l}\text { Квантовый } \\
\text { выход PL }\end{array}$ & $\begin{array}{c}\text { Время затухания } \\
\text { PL, ns }\end{array}$ & $T, \mathrm{~K}$ & Литература \\
\hline $\mathrm{CQD} \sim 2.5 \mathrm{PEG}$ & $\mathrm{H}_{2} \mathrm{O}$ & 21280 & $<0.1$ & - & RT & 27 \\
\hline CQD $\mathrm{ZnS} 2.5$ & $\mathrm{H}_{2} \mathrm{O}$ & 20000 & 0.78 & 6.0 & RT & 33 \\
\hline $\mathrm{CQD}<5.0$ & $\mathrm{H}_{2} \mathrm{O}$ & 19610 & 0.40 & - & RT & 34 \\
\hline $\mathrm{CQD} \sim 2.5$ & $\mathrm{H}_{2} \mathrm{O}$ & 23000 & 0.43 & - & RT & 35 \\
\hline CQD 1.25 & $\mathrm{H}_{2} \mathrm{O}$ & 21978 & 0.26 & - & $\mathrm{RT}$ & 36 \\
\hline CQD 0.85 & $\mathrm{H}_{2} \mathrm{O}$ & 23256 & 0.316 & 6.76 & RT & 37 \\
\hline CQD 2.5 & $\mathrm{H}_{2} \mathrm{O}$ & 22730 & 0.45 & 7.1 & RT & 38 \\
\hline MgNCQD 0.8 & $\mathrm{H}_{2} \mathrm{O}$ & 22880 & 0.83 & - & RT & 39 \\
\hline CQD 1.15 & $\mathrm{H}_{2} \mathrm{O}$ & 20830 & 0.51 & - & RT & 40 \\
\hline CQD 0.74 & PEG & 30770 & 0.21 & - & RT & 41 \\
\hline CQD 2.0 & $\mathrm{H}_{2} \mathrm{O}$ & 15625 & 0.162 & 0.68 & RT & 42 \\
\hline CQD & PVA & 20000 & 0.61 & 11.4 & RT & 43 \\
\hline CQD IS & $\mathrm{CH}_{3} \mathrm{OH}$ & 21700 & 0.28 & 13 & RT & 44 \\
\hline CQD IS & $\mathrm{CH}_{3} \mathrm{OH}$ & 18000 & 0.44 & $\sim 9$ & RT & 44 \\
\hline $\mathrm{NCQD}<5.0^{1)}$ & PVA & 20000 & - & $3.8 \cdot 10^{8}$ & RT & 24 \\
\hline NCQD & PVA & 22270 & 0.436 & - & RT & 45,46 \\
\hline NCQD 4.5 & $\mathrm{H}_{2} \mathrm{O}$ & 22026 & 0.23 & 3.1 & RT & 47 \\
\hline NOCQD 4.6 & $\mathrm{H}_{2} \mathrm{O}$ & 22025 & 0.735 & 13.3 & $\mathrm{RT}$ & 48 \\
\hline NCQD 1.5 & $\mathrm{H}_{2} \mathrm{O}$ & 22573 & 0.60 & 13.7 & RT & 49 \\
\hline $\mathrm{NCQD} \sim 1.0-2.5$ & PU & $\sim 23000$ & 0.11 & $\sim 6.6$ & RT & 26 \\
\hline $\mathrm{NCQD} \sim 1.0-2.5^{2)}$ & PU & $\sim 23000$ & - & $\sim 5 \cdot 10^{6}$ & RT & 26 \\
\hline $\mathrm{NCQD} \sim 1.0-2.5^{1)}$ & PU & $\sim 20000$ & - & $\sim 8.7 \cdot 10^{6}$ & RT & 26 \\
\hline NCQD 1.7 & Порошок & 20400 & 0.29 & $<10^{3}$ & $\mathrm{RT}$ & 25 \\
\hline NCQD $1.7^{1)}$ & Порошок & $\sim 20400$ & 0.07 & $8.3 \cdot 10^{8}$ & RT & 25 \\
\hline NCQD 2.5 HAD & $\mathrm{C}_{7} \mathrm{H}_{8}$ & $\sim 19000$ & 0.60 & - & RT & 50 \\
\hline CQD 5.0 & Порошок & 21050 & - & 5.45 & RT & 51 \\
\hline Cu-CQD 5.0 & Порошок & 16130 & 0.17 & $10.4 \cdot 10^{3}$ & RT & 51 \\
\hline SiCu-CQD 5.0 & Порошок & 14993 & 0.47 & $16.9 \cdot 10^{3}$ & $\mathrm{RT}$ & 51 \\
\hline NPCQD 1.65 & $\mathrm{H}_{2} \mathrm{O}$ & 23923 & 0.175 & 7.8 & RT & 52 \\
\hline NPCQD DAP & $\mathrm{H}_{2} \mathrm{O}$ & 19608 & 0.32 & 4.8 & RT & 53 \\
\hline NPCQD & $\mathrm{H}_{2} \mathrm{O}$ & 20000 & 0.30 & - & RT & 54 \\
\hline NPCQD & $\mathrm{H}_{2} \mathrm{O}$ & 14600 & 0.78 & - & RT & 54 \\
\hline NCQD & $\mathrm{H}_{2} \mathrm{O}$ & 22950 & 0.53 & 10.5 & RT & 55 \\
\hline NSCQD & $\mathrm{H}_{2} \mathrm{O}$ & 24100 & 0.73 & 12.1 & RT & 56 \\
\hline NSCQD 2.25 & $\mathrm{H}_{2} \mathrm{O}$ & 23750 & 0.78 & 10 & RT & 57 \\
\hline NSCQD 2.8 & $\mathrm{H}_{2} \mathrm{O}$ & 22200 & 0.81 & - & RT & 58 \\
\hline SCQD 2.3 & $\mathrm{H}_{2} \mathrm{O}$ & 22727 & 0.67 & 11.26 & $\mathrm{RT}$ & 59 \\
\hline NOCQD & $\mathrm{H}_{2} \mathrm{O}$ & 16000 & 0.24 & $\sim 9.0$ & RT & 60 \\
\hline NCQD 0.975 & $\mathrm{C}_{2} \mathrm{H}_{5} \mathrm{OH}$ & 23256 & 0.75 & 14.2 & RT & 61 \\
\hline NCQD 1.875 & $\mathrm{C}_{2} \mathrm{H}_{5} \mathrm{OH}$ & 18692 & 0.58 & 11.3 & RT & 61 \\
\hline NCQD 3.34 & $\mathrm{C}_{2} \mathrm{H}_{5} \mathrm{OH}$ & 16556 & 0.12 & 6.8 & RT & 61 \\
\hline NOCQD 1-2 & $\mathrm{H}_{2} \mathrm{O}$ & 22730 & 0.50 & 3.2 & RT & 62 \\
\hline Gr CQD & $\mathrm{C}_{7} \mathrm{H}_{8}$ & 14925 & 0.02 & 5.4 & RT & 63 \\
\hline GrCQD & $\mathrm{C}_{7} \mathrm{H}_{8}$ & 13500 & - & 4.103 & RT & 63 \\
\hline GrCQD $1.7 \times 1.25$ & $\mathrm{H}_{2} \mathrm{O}$ & 23810 & 0.17 & - & RT & 64 \\
\hline GrNCQD 0.73 & $\mathrm{H}_{2} \mathrm{O}$ & 19802 & 0.74 & 5.0 & RT & 65 \\
\hline GrOCQD $2.5 \times 0.7$ & $\mathrm{C}_{2} \mathrm{H}_{5} \mathrm{OH}$ & 15924 & 0.53 & 10.8 & RT & 66 \\
\hline GrO-CQD TPA & PMMA & 22260 & 0.18 & 2 & RT & 67 \\
\hline GrO-CQD TPA & PMMA & 20003 & $\sim 0.02$ & $6.95 \cdot 10^{3}$ & RT & 67 \\
\hline CQD Polym $\sim 12$ & $\mathrm{H}_{2} \mathrm{O}$ & 24390 & 0.442 & 6.13 & RT & 68 \\
\hline
\end{tabular}

Примечание. 1) Фосфоресценция (Phosphorescence), ${ }^{2)}$ Замедленная флуоресценция (Delayed fluorescence). Сокращения, используемые в таблице: PL - фотолюминесценция (Photoluminescence), RT — комнатная температура, CQD - углеродная квантовая точка, NCQD - углеродная квантовая точка, допированная азотом, NPCQD - то же, допированная азотом и фосфором, GrCQD - углеродные квантовые точки, построенные из графеновых блоков, PEG - полиэтиленгликоль с аминами на концах (diamine-terminated oligomeric poly-(ethylene glycol)) $\mathrm{H}_{2} \mathrm{NCH}_{2}\left(\mathrm{CH}_{2} \mathrm{CH}_{2} \mathrm{O}\right)_{n} \mathrm{CH}_{2} \mathrm{CH}_{2} \mathrm{CH}_{2} \mathrm{NH}_{2} \mathrm{H}_{2}$, PVA - поливиниловый спирт (polyvinyl alcohol), $\mathrm{PU}$ - полиуретан (polyurethane), $\mathrm{C}_{7} \mathrm{H}_{8}-$ толуол (toluene), PMМА - полиметилметакрилат (polymethylmethacrylate), ТPA — трифениламин (triphenylamine), GrO — окисленный графен (охіdized graphene). 
выход PL в видимой области спектра (табл. 1). В 2013 г. Дэнг с соавторами [25] обнаружил, что CQD в матрице поливинилого спирта кроме PL, затухающей за наносекунды, обладают также длительной фосфоресценцией с временами, достигающими сотен миллисекунд. Позднее Ли с соавторами [25] подтвердили эти наблюдения и предложили для объяснения схему электронных уровней, аналогичную схеме трех уровней ЯблонскогоТеренина-Льюиса для органических молекул: основного невозбужденного синглетного и нижних возбужденных синглетного и триплетного уровней [19,28-31] (рис. 1 и табл. 1$)$.

В том же году Тан и соавторы [24-26], работая с набором синтезированных ими CQD в полиуретановой матрице, обнаружили не только фосфоресценцию, но и впервые их замедленную флуоресценцию. Было также установлено сильное тушение фосфоресценции точек атмосферным кислородом. Наличие фосфоресценции у квантовых точек, построенных из окисленного графена, было обнаружено и изучено в работе Цхао и соавторов [32] (табл. 1).

В табл. 1 собраны данные о выходах флуоресценции различных CQD. Приводятся также данные о фосфоресценции, если в оригинальной работе они имеются. В таблице указаны также сведения о размерах точки, растворителе, положении максимума полосы люминесценции в обратных сантиметрах, длительности свечения, температуре и литературном источнике.

Ниже приведены краткие дополнительные сведения о квантовых точках, приведенных в табл. 1. Као и Янг с соавторами [34,35], используя CQD диаметром менее $10 \mathrm{~nm}$, получили выходы флуоресценции больше 40\%. Высокий выход флуоресценции CQD, синтезированных из апельсинового сока и желатины, получен также в работах Саху и Лианг с соавторами [36,37]. Ли с соавторами [38] удалось получить образцы с высоким выходом PL и спектром, не зависящим от длины волны возбуждающего света. Квантовый выход флуоресценции CQD в воде удалось еще существеннее поднять, сочетая пассивацию этилендиамином с внедрением в них $\mathrm{Mg}^{2+}$ [39]. Фенг и соавторы [40] синтезировали из тиосалициловой кислоты и этилендиамина CQD, имеющие высокий квантовый выход PL, близкой по составу к белому свету. В работе Нгуён и соавторов [41] реализован новый метод синтеза CQD, люминесцирующих в УФ области спектра, из порошка графита с помощью фемтосекундного лазера. Синтез уникальных CQD, излучающих в красной области спектра с заметным квантовым выходом, описан в работе Сан и соавторов [42].

Простой метод внедрения CQD в полимерную среду с сохранением высокого квантового выхода для создания сверхтонких ярко люминесцирующих гибких слоев описан в работе Дзианга и соавторов [43]. Авторы работы [44] синтезировали квантовые точки с высоким выходом флуоресценции, излучающие в желтой области спектра, в комбинации с которыми возможно создание эффективных источников белого света на базе CQD. Оуджай и соавторы $[45,46]$ разработали простой и быстрый гидротермальный синтез из лимонной кислоты и мочевины допированных азотом CQD, обладающих высоким квантовым выходом синей флуоресценции. В работах Уанг и Ске с соавторами $[47,48]$ были предложены упрощенные методы получения CQD, активированных азотом и кислородом и обладающих высоким квантовым выходом. Гидротермальным синтезом из лимонной кислоты и этилендиамина получены допированные азотом квантовые точки с квантовым выходом голубой флуоресценции, достигающим $60 \%$ [49].

В работе [50] синтезировали квантовые точки, излучающие белый свет с высоким квантовым выходом флуоресценции, пригодные для использования в электролюминесцентных устройствах. Фан и соавторы [51] синтезировали квантовые точки, которые имеют структуру полых сфер и в присутствии $\mathrm{Cu}^{+}$люминесцируют с высоким выходом в красной области спектра.

Серия работ посвящена CQD, одновременно допированным азотом и фосфором [52-54]. Высокий выход флуоресценции был получен также и при допировании точки только азотом [55]. Совместное допирование точек азотом и серой позволило достичь еще более высоких выходов флуоресценции и использовать зависимость ее интенсивности от температуры для создания флуоресцентного нанотермометра [56-58].

Методом гидротермального синтеза из лимоннокислого натрия и тиосульфата натрия были синтезированы квантовые точки, допированные только серой и флуоресцирующие в синей области с выходом 0.67 [59]. Окисление поверхности CQD кислородом позволило получить образцы, спектры флуоресценции которых варьировали от 440 до $625 \mathrm{~nm}$ в зависимости от степени окисления поверхности, а не размера точки, при выходе $35 \%$ [60]. Высокий выход PL квантовых точек был получен для столь же широкой области спектра за счет изменения их размера [61]. Уанг и соавторы [62], исследуя синтезированные ими CQD из лимонной кислоты и различных диаминов, пришли к заключению, что высоким выходом флуоресценции обладают структуры производных пирамидона.

Значительная часть CQD была синтезирована на основе графеновых структур. В конце табл. 1 приведен ряд данных для такого типа CQD. От обычных CQD графеновые отличаются тем, что они не шарообразные, а являются круглыми дисками, состоящими из одного или нескольких графеновых слоев во многих случаях с дефектами, вызванными включениями в графеновую структуру групп с кислородом или азотом. Муэллер и соавторы [63] показали, что синтезированные им графеновые квантовые точки при их фотовозбуждении имеют заметную вероятность интеркомбинационной конверсии в триплетное состояние и фосфоресцируют. К сожалению, выход их суммарной люминесценции 
Таблица 2. Процессы быстрой релаксации в CQD

\begin{tabular}{|c|c|c|c|c|c|c|c|}
\hline $\begin{array}{c}\text { Квантовая } \\
\text { точка }\end{array}$ & $R, \mathrm{~nm}$ & Растворитель & $v_{\mathrm{exc}}, \mathrm{cm}^{-1}$ & $\begin{array}{l}v_{\text {reg }}, \mathrm{PL} \\
\mathrm{TA}, \mathrm{cm}^{-1}\end{array}$ & $\begin{array}{c}\tau_{n} \text { времена } \\
\text { затухания, ps }\end{array}$ & $T, \mathrm{~K}$ & Литература \\
\hline CQD & $<40$ & Слой & 24682 & PL15406-21052 & $\begin{array}{c}\tau_{1}<1.0 \\
\tau_{2}=2400\end{array}$ & RT & 71 \\
\hline OCQD & 1 & $\mathrm{H}_{2} \mathrm{O}$ & 25000 & PL16667 & $\begin{array}{l}\tau_{1} \sim 0.61 ; \tau_{2} \sim 4 \\
\tau_{3} \sim 29 ; \tau_{4}>500\end{array}$ & RT & 72 \\
\hline ONCQD & $1-2$ & $\mathrm{H}_{2} \mathrm{O}$ & 25840 & TA 22730 & $\begin{array}{c}\tau_{1}=1.3 ; \tau_{2}=13 \\
\tau_{3}=3200\end{array}$ & RT & 73 \\
\hline GrCQD & $3-5$ & $\mathrm{H}_{2} \mathrm{O}$ & 25000 & PL21276 & $\begin{array}{c}\tau_{1}=0.2-1.6 \\
\tau_{2}=4 \cdot 10^{3}\end{array}$ & RT & 74 \\
\hline GrOCQD & - & $\mathrm{H}_{2} \mathrm{O}$ & 17544 & TA19231 & $\tau_{1}=0.11 ; \tau_{2}=1.1$ & RT & 75 \\
\hline GrCQD & - & $\mathrm{H}_{2} \mathrm{O}$ & 17544 & TA19231 & $\tau_{1}=0.120 ; \tau_{2}=1.4$ & RT & 75 \\
\hline GrOCQD & $10^{3}$ & $\mathrm{C}_{2} \mathrm{H}_{5} \mathrm{OH}$ & 25000 & TA20000 & $\begin{array}{c}\tau_{1}=4.1 ; \tau_{2}=33.5 \\
\tau_{3}=282.6\end{array}$ & RT & 67 \\
\hline
\end{tabular}

Примечание. PL - измерения быстрой кинетики по фотолюминесценции, TA - измерения быстрой кинетики по изменению спектров поглощения (transition absorption), $v_{\text {exc }}$ - частота возбуждающего фотона, $v_{\text {reg }}$ - частота регистрации кинетики. Остальные сокращения - в примечаниях к табл. 1.

при комнатной температуре в обескислороженном толуоле всего $2 \%$ и становится еще меньше в растворе в бромбензоле. Авторы исследования предполагают, что интеркомбинационная конверсия осуществляется не только между $S_{1-}$ и $T_{1}$-уровнями, но и между высокими возбужденными синглетными и триплетными уровнями. Однако приведенные ими экспериментальные данные не позволяют полностью согласиться с данным выводом.

Используя гидротермальный синтез с глюкозой и серной кислотой, Янг и соавторы [64] получили графеновые квантовые точки, имеющие две полосы флуоресценции около 26215 и $20488 \mathrm{~cm}^{-1}$, не зависящие от $\mathrm{pH}$ и имеющие выход флуоресценции около 17\%. Значительно больший выход флуоресценции (74\%) получили у графеновых квантовых точек, допированных азотом, Денг и соавторы [65]. В то же время длительность флуоресценции (в отличие от времени затухания красителей) сильно зависит от длины волны излучения квантовой точки, имея $5 \mathrm{nc}$ в максимуме спектра и спадая до $\sim 2 \mathrm{nc}$ по краям. Ванг и соавторы [66] синтезировали на основе оксипроизводных нафталина квантовые точки, обладающие графеновыми структурами с высоким (53\%) выходом флуоресценции в красной области. На основе этих и ранее предложенных CQD, люминесцирующих в голубой и зеленой областях спектра, сконструирован макет излучателя теплого белого света с высокой световой отдачей. В работе [67] была исследована кинетика флуоресценции и фосфоресценции квантовых точек из окиси графена, пассивированых трифениламином. Помещенные в полимер (РММА), они обнаруживают флуоресценцию с выходом 0.18 и фосфоресценцию с выходом 0.02 и длительностью 6.95 мкс. Сшивая гидро- термальным методом полиакриловую кислоту и этилендиамин, авторы работы [68] получили новые полимерные квантовые точки с квантовым выходом флуоресценции больше $44 \%$.

\section{Процессы релаксации в CQD}

Представляет интерес сравнить данные о скоростях релаксации энергии электронного возбуждения в CQD с аналогичными процессами в сложных органических молекулах в растворах. В работах, посвященных изучению скоростей релаксации с высоких возбужденных синглетных уровней в молекулах в конденсированном состоянии, установлено, что (за исключением небольшой группы молекул: азулены, тиокетоны, некоторые порфины, в которых релаксация со второго синглетного уровня на $S_{1}$ одного порядка с излучением с него на $S_{0}$ ) для большинства молекул скорости релаксации со второго и более высоких синглетных уровней на три-четыре порядка больше скоростей излучения с них $[69,70]$.

В табл. 2 собраны выборочные данные о быстрых процессах релаксации в CQD после поглощения ими кванта, энергия которого больше энергетического зазора между валентной зоной и зоной проводимости.

В работе Немек и соавторы [71] методами фемтосекундного лазерного фотолиза и ап-конверсионного возбуждения PL изучены первичные процессы релаксации в алмазных квантовых точках. Было установлено, что PL и наведенное поглощение в первый момент после возбуждения импульсом обнаруживают быстрый спад за время менее $1 \mathrm{ps}$, что авторы приписывают быстрому пространственному расхождению электрона и дырки, затрудняющему их рекомбинации с излучением. Более 
медленное затухание $(2.4 \mathrm{~ns})$ флуоресценции в полосе около $1.68 \mathrm{eV}$ приписывается излучению кремниевой ловушки. Суи и соавторы [72] использовали метод фемтосекундного лазерного фотолиза для исследования водных растворов CQD диаметром $2 \mathrm{~nm}$. Были зафиксированы четыре временных процесса затухания, и авторы интерпретировали процессы следующим образом.

1. Рассеяние горячего электрона на электронах и захват на поверхностной ловушке $(<1 \mathrm{ps})$.

2. Взаимодействие с оптическими фононами ( $4 \mathrm{ps})$.

3. Взаимодействие с акустическими фононами ( десятки пикосекунд).

4. Рекомбинация электрона и дырки ( наносекунды) (табл. 2).

Уанг и соавторы [73], исследуя сверхбыстрые процессы в графеновых квантовых точках, пришли к заключению, что осуществляющийся за 1.5 ps после поглощения света процесс соответствует переносу энергии от ядра точки к периферической пирамидоновой молекулярной структуре. В работе [74] были изучены с помощью пикосекундных измерений PL и фемтосекундного лазерного фотолиза графеновые квантовые точки. Полученные данные были интерпретированы как наличие короткоживущей слабой люминесценции $(0.2-1.6 \mathrm{ps})$, соответствующей рекомбинации носителей, и интенсивного излучения наносекундной длительности, обусловленного центрами молекулярного типа, которые захватывают экситоны. Цханг и Луо [75] изучали фемтосекундные фотопроцессы в квантовых точках, построенных из исходного и окисленного графена. Как видно из приведенных в табл. 2 данных, первичные процессы после поглощения протекают в них за время около сотни фемтосекунд и немногим больше пикосекунды в обоих объектах.

Авторы работы [67] изучали фосфоресценцию от квантовых точек, построенных из обычного и окисленного графена, в том числе пикосекундные процессы заселения триплетного состояния.

\section{Кремниевые квантовые точки}

Кахам [76] первый обнаружил красную PL у пористого кремния и интерпретировал ее как обусловленную квантово-размерным эффектом. Брас и сотрудники $[77,78]$ обнаружили интенсивную PL кремниевых квантовых точек, синтезированных кристаллизацией из газовой фазы. Они измерили выходы и кинетику ее затухания в этиленгликоле при различных температурах. Поверхность точек была пассивирована предварительным окислением до $\mathrm{SiO}_{2}$, тем не менее выход флуоресценции при комнатной температуре не превышал 5-6\%. Было также установлено наличие сдвига спектров PL, обусловленного квантово-размерными ограничениями.

Громадный материал о квантовых точках на основе кремния собран в недавно вышедшей монографии Ищенко и соавторов [8,9]. Совсем недавно вышел также обстоятельный обзор Сирони и сотрудников [79], посвященный, в частности, методам повышения яркости свечения кремниевых квантовых точек путем переноса энергии на них от красителей, а также ряду применений таких систем. В табл. 3 собраны данные о квантовых точках на основе кремния, которые обладают заметными выходами люминесценции.

В 2002 г. Ледо и соавторы [80] определили квантовые выходы PL кремниевых квантовых точек диаметром от 2.5 до $8.0 \mathrm{~nm}$, нанесенных на кварц и пассивированных окислением кислородом (табл. 3). Квантовые выходы были максимальными (около 30\%) для диаметра $3.5 \mathrm{~nm}$, слегка падали при уменьшении размера и систематически падали с увеличением размеров точек (до долей процента для точек размером $8 \mathrm{~nm}$ ).

Валента и соавторы [81] сумели измерить спектры и выходы отдельных квантовых точек. Для наиболее интенсивно светящейся точки они оценили квантовый выход в 35\%, в то же время многие точки имеют существенно меньший выход или даже совсем не светятся.

В работах Кортшагена с сотрудниками [82,83] был разработан синтез и пассивация кремниевых квантовых точек, исключающие их окисление, позволившие для точек с максимумом флуоресценции в красной области около $800 \mathrm{~nm}$, пассивированных 1-деценом, достичь квантового выхода более $60 \%$ (табл. 3). При этом для кремниевых квантовых точек, хорошо люминесцирующих в длинноволновой области спектра, при переходе к точкам, излучающим в более коротковолновой области (около $700 \mathrm{~nm}$ ), выход флуоресценции падает почти до нуля.

В работе [84] оценены выходы PL кремниевых квантовых точек, внедренных в кварц различной толщины. Авторы работы [85] предложили новый метод синтеза кремниевых квантовых точек, спектр излучения которых охватывает всю видимую область спектра, а излучение стабильно сохраняется в течение длительного времени на воздухе. Кортшаген и Антони [86] установили, что аморфные кремниевые квантовые точки обладают очень слабой PL $\left(q_{\mathrm{PL}}<2 \%\right)$, и по мере кристаллизации выход растет до $\sim 40 \%$. Для дальнейшего повышения выхода PL предлагается два метода пассивации поверхности кремниевой точки: с помощью органических соединений и естественного процесса окисления поверхности.

Дохнавалова и соавторы [87] исследовали изменения спектров и длительности PL в процессе быстрого окисления кремниевых квантовых точек с водородами на концах валентных связей. При этом полоса люминесценции около $525 \mathrm{~nm}$ с длительностью в наносекундной области постепенно уменьшалась, и одновременно появлялась люминесценция в красной области спектра $(660 \mathrm{~nm})$ с длительностью в области микросекунд. Коротковолновая полоса интерпретирована как следствие рекомбинации электрона и дырки в ядре квантовой точки, а ее тушение объяснена сверхбыстрым захватом экситона поверхностным уровнем, связанным с кислородом. 
Таблица 3. Квантовые выходы и времена затухания люминесценции квантовых точек на основе кремния

\begin{tabular}{|c|c|c|c|c|c|c|}
\hline $\begin{array}{c}\text { Квантовая точка, } \\
\text { лиганд, радиус, nm }\end{array}$ & Растворитель & $\begin{array}{l}\text { Частота макс. } \\
\text { PL, } \mathrm{cm}^{-1}\end{array}$ & $\begin{array}{c}\text { Квантовый } \\
\text { выход PL }\end{array}$ & $\begin{array}{c}\text { Время затухания } \\
\text { PL, ns }\end{array}$ & $T, \mathrm{~K}$ & Литература \\
\hline SiQD $1.5-4.0$ & $\mathrm{EG}+\mathrm{GL}$ & 16130 & 0.056 & $5.0 \cdot 10^{4}$ & RT & 77 \\
\hline $\mathrm{SiQD} 1.5-4.0$ & $\mathrm{EG}+\mathrm{GL}$ & 16130 & 0.50 & $2.5 \cdot 10^{6}$ & $<50$ & 77 \\
\hline SiQD 1.75 & Слой & 14520 & $\sim 0.3$ & - & RT & 80 \\
\hline SiQD 1.8 & $\mathrm{SiO}_{2}$ & 13712 & 0.35 & - & RT & 81 \\
\hline SiQD 1.95 & $\mathrm{C}_{9} \mathrm{H}_{12}$ & 12674 & 0.62 & - & RT & 82 \\
\hline $\mathrm{SiQD} \sim 2.0$ & $\mathrm{C}_{6} \mathrm{H}_{14}$ & 12500 & $\sim 0.65$ & - & RT & 83 \\
\hline $\mathrm{SiQD} \sim 1.55$ & $\mathrm{C}_{6} \mathrm{H}_{14}$ & 14285 & $\sim 0.01$ & - & RT & 83 \\
\hline $\mathrm{SiQD}$ & $\mathrm{SiO}_{2}$ & 13333 & 0.59 & $\sim 5.9 \cdot 10^{4}$ & RT & 84 \\
\hline $\mathrm{SiQD} \sim 3.0$ & $\mathrm{CH}_{3} \mathrm{OH}$ & 14800 & 0.16 & $1.4 \cdot 10^{4}$ & RT & 85,86 \\
\hline ONCSiQD 17.5 & $\mathrm{H}_{2} \mathrm{O}$ & 19230 & 0.25 & - & RT & 88 \\
\hline $\mathrm{SiQD} 2.1$ & $\mathrm{SiO}_{2}$ & - & 0.65 & - & RT & 89 \\
\hline SiQD 1.3 & $\mathrm{C}_{6} \mathrm{H}_{14}$ & 15400 & 0.13 & $7.6 \cdot 10^{4}$ & RT & 90 \\
\hline SiQD 1.6 & $\mathrm{C}_{6} \mathrm{H}_{14}$ & 12200 & 0.37 & - & RT & 90 \\
\hline SiQD 1.9 & $\mathrm{C}_{6} \mathrm{H}_{14}$ & 10870 & 0.33 & - & RT & 90 \\
\hline CaNCSiQD 1.25 & $\mathrm{H}_{2} \mathrm{O}$ & 20000 & 0.75 & 31 & RT & 91 \\
\hline $\mathrm{SiQD} \sim 5.0$ & $\mathrm{C}_{7} \mathrm{H}_{8}$ & 15873 & 0.51 & $\sim 10^{3}$ & RT & 92 \\
\hline SiQD 1.85 & $\mathrm{H}_{2} \mathrm{O}$ & 20000 & 0.13 & - & RT & 93 \\
\hline $\mathrm{SiQD}$ & $\mathrm{SiO}_{2}$ & 10486 & 0.19 & - & RT & 94 \\
\hline SiQD 1.5 & $\mathrm{C}_{7} \mathrm{H}_{8}$ & 11857 & 0.6 & $9 \cdot 10^{4}$ & RT & 95 \\
\hline SiQD 2.75 & $\mathrm{C}_{7} \mathrm{H}_{8}$ & 14680 & 0.35 & $4.5 \cdot 10^{4}$ & RT & 95 \\
\hline NSiQD 2.25 & $\mathrm{SiO}_{2}$ & 11696 & 0.2 & $1.4 \cdot 10^{5}$ & RT & 96 \\
\hline ONSiQD 2.6 & $\mathrm{H}_{2} \mathrm{O}$ & 18000 & 0.90 & 3 & RT & 97 \\
\hline SiQD 1.95 & $\mathrm{C}_{6} \mathrm{H}_{14}$ & 13890 & 0.37 & $6.5 \cdot 10^{4}$ & RT & 98 \\
\hline SiQD 1.6 & $\mathrm{C}_{6} \mathrm{H}_{14}$ & 15380 & 0.11 & $4.5 \cdot 10^{4}$ & RT & 99 \\
\hline $\mathrm{SiQD} 2.25 \mathrm{DC}$ & $\mathrm{C}_{7} \mathrm{H}_{8}$ & 12099 & 0.6 & $2.5 \cdot 10^{5}$ & RT & 100 \\
\hline
\end{tabular}

Примечание. SiQD - квантовая точка на основе кремния, ONCSiQD - окисленная кремниевая квантовая точка, активированная азотом и углеродом, EG - этиленгликоль (ethylene glycol), GL - глицерин (glycerol), $\mathrm{C}_{9} \mathrm{H}_{12}-$ триметилбензол (trimethylbenzene), $\mathrm{C}_{6} \mathrm{H}_{14}-$ гексан (hexane), $\mathrm{C}_{7} \mathrm{H}_{8}$ - толуол (toluene), DC - додецен (dodecene).

В работе [88] синтезированы кремниевые квантовые точки, которые хорошо растворяются в воде, обладают достаточно высоким квантовым выходом люминесценции, слабо зависящим от $\mathrm{pH}$, и устойчивы к интенсивному облучению. Работа [89] посвящена изучению нарастания выхода флуоресценции кремниевых квантовых точек размером $4.17 \mathrm{~nm}$ после приготовления и последовательной пассивации окислением. Нарастание квантового выхода PL продолжается месяц и достигает величины 0.65. Авторы работы [90] исследовали влияние давления на спектры PL квантовых точек и установили их смещение в красную сторону при увеличении давления, что аналогично поведению энергетического зазора в массивном кремнии. Дальнейшее повышение квантового выхода PL кремниевых нанокристаллов до 75\% осуществили Ли и соавторы [91] путем модификации поверхности со связями $\mathrm{Si}-\mathrm{Cl}$ карбазолом в присутствии кислорода. Повышение выхода сопровождается удлинением времени затухания свечения до $31 \mathrm{~ns}$, протекающего по моноэкспоненциальному закону. Сходное, но меньшее $(50 \%)$ повышение выхода и времени затухания PL дает реакция с дифениламином. Используя экспоненциальный закон затухания модифицированных квантовых точек и зависимость времени затухания их люминесценции от температуры водного раствора, авторы [91] предлагают на их основе чувствительный люминесцентный термометр для области $0.5-60^{\circ} \mathrm{C}$.

Были также предложены [92] варианты кремниевых точек, обладающих значительным выходом PL и широким спектром в районе $613 \mathrm{~nm}$ для разработки источников теплого белого света. С той же целью в работе [93] предложены точки, излучающие в желтозеленой области, имеющие значительный выход PL и хорошую стабильность при облучении УФ светом. Валента и соавторы [94] сравнили выходы PL сплошной среды $\mathrm{SiO}_{2}$ с внедренными силикатными нанокристаллами, с такой же системой, в которой тонкие слои с нанокристаллами перемежались изолирующими слоями $\mathrm{SiO}_{2}$. Было установлено, что когда толщина изолирующих слоев достигла $2 \mathrm{~nm}$, выход PL при комнатной температуре увеличился вдвое по сравнению с отсутствием изолирующих слоев. Изучая кинетику затухания и выходы PL кремниевых нанокристаллов, пассивированных гексилом (hexyl), додецилом (dodecyl) или метилдеканоатон (methyl undecanoate), авторы [95,96] пришли к выводу, что внутренний квантовый выход „светящихся“ точек равен единице, а измеряемый внешний выход определяется наличием „темных“ точек. 
Таблица 4. Процессы релаксации в кремниевых квантовых точках

\begin{tabular}{|c|c|c|c|c|c|c|c|}
\hline Квантовая точка & Радиус, nm & Растворитель & $v_{\mathrm{exc}}, \mathrm{cm}^{-1}$ & $v_{\text {reg }}, \mathrm{cm}^{-1}$ & Время затухания, ps & $T, \mathrm{~K}$ & Литература \\
\hline SiQD & 1.4 & $\mathrm{SiO}_{2}$ & 25000 & TA12906 & $\tau_{1}=1.5 ; \tau_{2}=8$ & RT & 102 \\
\hline SiQD & $1-2.5$ & $\mathrm{SiO}_{2}$ & 25000 & PL15873 & $\tau_{1}=0.4 ; \tau_{2}=16$ & RT & 103 \\
\hline $\mathrm{SiQD}$ & $1-2.5$ & $\mathrm{SiO}_{2}$ & 28169 & PL14706 $^{1)}$ & $\tau_{3} \sim 10^{6}-10^{7}$ & RT & 103 \\
\hline OSiQD & 2.0 & $\mathrm{SiO}_{2}$ & 25000 & $\begin{array}{l}\text { TA20000; } \\
12500\end{array}$ & $\begin{array}{c}\tau_{1}=1.5 ; \tau_{2}=13 \\
\tau_{1}=0.5 ; \tau_{2}=3\end{array}$ & RT & 104 \\
\hline SiQD & $<2.0$ & $\mathrm{C}_{6} \mathrm{H}_{14}$ & 25000 & PL20000 & $\begin{array}{l}\tau_{1}=0.38 \\
\tau_{2}=5000\end{array}$ & RT & 105 \\
\hline SiQD & 2.1 & $\mathrm{C}_{6} \mathrm{H}_{12}$ & 25641 & $\begin{array}{l}\text { TA18182; } \\
\text { TA16666; } \\
\text { TA21277; } \\
\text { PL21277 }\end{array}$ & $\begin{array}{c}\tau_{1}=0.57 \\
\tau_{2}=4.0 \\
\tau_{3}=110 \\
\tau_{4}=2500\end{array}$ & RT & 106 \\
\hline SiQD 3ETP & 2.2 & $\mathrm{C}_{6} \mathrm{H}_{12}$ & 25641 & $\begin{array}{l}\text { TA22222; } \\
\text { TA15385 }\end{array}$ & $\tau_{1}=0.6 ; \tau_{2}=20$ & RT & 107 \\
\hline OSiQD 3ETP & $1-1.5$ & $\mathrm{C}_{2} \mathrm{H}_{5} \mathrm{OH}$ & 25865 & TA15380 & $\begin{array}{c}\tau_{1}=0.5 ; \tau_{2}=18 \\
\tau_{3}=220 ; \\
\tau_{4}=1250\end{array}$ & RT & 108 \\
\hline SiQD 3AT & 1.7 & $\mathrm{H}_{2} \mathrm{O}$ & 25000 & TA18690 & $\begin{array}{l}\tau_{1}=0.2 ; \tau_{2}=2.4 \\
\tau_{3}=32 ; \tau_{4}=3700\end{array}$ & RT & 109 \\
\hline OSiQD 2VP & 1.25 & $\mathrm{C}_{2} \mathrm{H}_{5} \mathrm{OH}$ & 25840 & TA18519 & $\tau_{1}=0.45 ; \tau_{2}=110$ & RT & 110 \\
\hline SiQD 1-D & 1.6 & $\mathrm{C}_{8} \mathrm{H}_{18}$ & 30769 & $\mathrm{PL} \sim 20000$ & $\tau_{1}=30 ; \tau_{2}=243$ & RT & 111 \\
\hline SiQD-H & 1.25 & $\mathrm{H}_{2} \mathrm{O}$ & 25000 & $\begin{array}{l}\text { TA22988; } \\
\text { TA14922 }\end{array}$ & $\begin{aligned} \tau_{1} & >5 \\
\tau_{2} & \sim 1\end{aligned}$ & RT & 114 \\
\hline SiQD-D & 1.25 & $\mathrm{D}_{2} \mathrm{O}$ & 25000 & $\begin{array}{l}\text { TA22988; } \\
\text { TA14922 }\end{array}$ & $\begin{array}{l}\tau_{1}=5 \\
\tau_{2} \sim 1\end{array}$ & RT & 114 \\
\hline $\mathrm{SiQD}-\mathrm{Cz}$ & 1.25 & $\mathrm{H}_{2} \mathrm{O}$ & 25000 & TA20000 & $\begin{array}{c}\tau_{1}=1.2 ; \tau_{2}=9 \\
\tau_{3}=100 \\
\tau_{4}=1000\end{array}$ & RT & 116 \\
\hline OSiQD & 2.5 & $\mathrm{C}_{7} \mathrm{H}_{8}$ & 25000 & PL13774 & $\begin{array}{c}\tau_{1}=660 \\
\tau_{2}=4000 \\
\tau_{3}=44 \cdot 10^{6}\end{array}$ & RT & 117 \\
\hline
\end{tabular}

Примечание. $v_{\mathrm{exc}}$ - частота возбуждающего излучения, $v_{\mathrm{reg}}$ - частота регистрации PL или поглощения, TA - кинетика изменения поглощения (transition absorption), PL - фотолюминесценция (photoluminescence), SiQD — квантовые точки на основе кремния, OSiQD - кремниевые точки активированные кислородом. ${ }^{1)}$ Излучение от поверхностных состояний, $\mathrm{C}_{6} \mathrm{H}_{12}$ - циклогексан, 3ETP - 3-этинилтиофен (3-еthenylthiophene), $3 \mathrm{AP}$ - 3-аминопропилен (3-aminopropilene), 2VP - 2-винилпиридин (2-vinylpyridine), 1-D - 1-додекан (1-dodecane), $\mathrm{C}_{8} \mathrm{H}_{18}-$ октан (осtane), $\mathrm{Cz}$ - карбазол (carbazole), $\mathrm{C}_{7} \mathrm{H}_{8}$ - толуол.

Интересной работой, проясняющей ряд важных механизмов фотопроцессов в кремниевых квантовых точках стала работа Лаи и соавторов [97], исследовавших синтезированные ими объекты, обладающие квантовым выходом PL более 90\% при относительно малой ширине спектра $(40 \mathrm{~nm})$. Были изучены точки диаметром от 2.8 до $5.2 \mathrm{~nm}$, пассивированные различными ариламинами: карбазол, 1,2,3,4-тетрагидро-карбазол4-он, 4-аминоацетофенон, N-фенил-1,4-фенилендиамин. Было установлено, что во всех этих случаях положение спектра люминесценции не определяется размером частиц, а определяется поверхностными уровнями, на которые влияют пассивирующие лиганды. В работе Брауна и соавторов $[98,99]$ исследовано влияние растворителей на выходы PL кремниевых квантовых точек, люминесцирующих в красной области спектра с длительностью в десятки микросекунд. Было показано, что выход и длительность PL уменьшаются с увеличением донорной силы растворителя. Выход PL кремниевых квантовых точек, пассивированных 1-додеценом, для полосы $12100 \mathrm{~cm}^{-1}$ составил 0.6 [100].

Рассматривая данные табл. 3, видно, что длительности основного свечения большинства кремниевых точек попадают в область микросекунд, т. е. соответствующий 
излучательный переход является запрещенным в электрическом дипольном приближении. В работе Кусовой и соавторов [101] предлагается метод существенного увеличения вероятности излучательного перехода в кремниевых квантовых точках, используя растягивающую деформацию кристаллического ядра квантовой точки, которая приближает ее оптические свойства к таковым прямозонных полупроводников.

\section{Релаксация в кремниевых квантовых точках}

В данном разделе будет дан краткий обзор работ, посвященных исследованию процессов релаксации в кремниевых квантовых точках, выборочные данные о которых сведены в табл. 4.

Первые исследования быстропротекающих процессов релаксации, имеющие место в кремниевых квантовых точках, были осуществлены Климовым и сотрудниками в 1998 г. [102]. Были изучены спектры наведенного поглощения квантовых точек размером 2.5-3 и 5-6 nm под излучением титанового лазера с длиной волны $400 \mathrm{~nm}$. В красной области спектра были обнаружены две наведенные полосы поглощения, затухающие после возбуждения по биэкспоненциальному закону с временами 1.5 и 8 ps (табл. 4). Троянек и соавторы [103] изучали быструю кинетику PL в кремниевых нанокристаллах методом фемтосекундной ап-конверсии. Для нанокристаллов диаметром 2-5 nm обнаружены два быстрых спада интенсивности люминесценции. Первый, с временем затухания $400 \mathrm{fs}$, отнесен к взаимодействию первичного электронного возбуждения с оптическими фононами. Второй, длительностью $16 \mathrm{ps}$, отнесен к захвату экситона поверхностной ловушкой. Длительность люминесценции при излучении с нее составляет в зависимости от частоты от 3 до 40 мкс. В статье Лиоудакиса и соавторов [104] изучены релаксации наведенного поглощения после $100 \mathrm{fs}$ импульса в квантовых точках диаметром 4.0 и $2.5 \mathrm{~nm}$. Релаксация неплохо описывается двумя экспонентами (табл. 4). Обнаружена линейная зависимость скорости затухания обеих экспонент наведенного поглощения от частоты зондирующего луча. Климов и сотрудники [105] исследовали быстрый (< $5 \mathrm{~ns})$ спад интенсивности коротковолнового края спектра люминесценции кремниевых квантовых точек размером меньше $4 \mathrm{~nm}$ и пришли к заключению, что данное излучение с $\tau \sim 0.39 \mathrm{ps}$ обусловлено рекомбинацией электрона и дырки во внутреннем ядре квантовой точки, в то время как более длинноволновая PL c $\tau \geq 5 \mathrm{~ns}$ обусловлена излучением поверхностных уровней.

В работе Кунтермана и соавторов [106] методом фемтосекундного лазерного фотолиза изучена релаксация кремниевых квантовых точек среднего размера $4.1 \mathrm{~nm}$ в кварцевой среде. Установлено наличие двух процессов быстрой релаксации (0.57 и $4.0 \mathrm{ps})$, интерпретированных как электрон-фононная релаксация и захват электрона поверхностными состояниями соответственно. Кроме того, авторы зарегистрировали по поглощению и флуоресценции два более медленных процесса релаксации (табл. 4). Продолжая данные исследования, та же группа подробно изучила кинетику процессов в кремниевых квантовых точках размером $2.2 \mathrm{~nm}$, пассивированных 3-этенилтиофеном [107]. Авторы обнаружили процессы длительностью 0.6 и 20 ps, которые были интерпретированы как электрон-фононное взаимодействие и процесс захвата возбуждения поверхностной ловушкой. В следующей работе та же группа [108] изучала кремниевые квантовые точки, окруженные 3-винилтиофеном. Изучая кинетику переходных спектров поглощения под действием фемтосекундных импульсов, авторы обнаружили $0.6 \mathrm{ps}$ процесс нарастания, интерпретированный как передача энергии от 3-винилтиофена к ядру точки, и приведенные в табл. 4 четыре различных кинетики затухания возбужденных состояний точки с временами от 0.5 до $1250 \mathrm{ps}$. Столько же кинетик затухания выявлено в работе [109], в которой были изучены синтезированные авторами за $12 \mathrm{~h}$ с помощью воздействия микроволнового облучения кремниевые квантовые точки, пассивированные 3-аминопропиленом.

Окисленные кремниевые квантовые точки, пассивированные 2- или 4-винилпиридинами, были изучены в работе [110]. Первичный быстрый процесс релаксации протекал за времена $0.45-0.6 \mathrm{ps,} \mathrm{следующий,} \mathrm{более}$ медленный процесс - 110 или 177 ps в зависимости от лиганда. Ханнах и соавторы [111-113] исследовали сверхбыстрые процессы излучения в сине-зеленой полосе люминесценции кремниевых квантовых точек диаметром $3.2 \mathrm{~nm}$ и установили, что данное излучение затухает за 30 ps. В отличие от основной красной полосы PL, которая обусловлена кристаллическим ядром точки и затухает за микросекунды, это свечение авторы связывают с аморфной составляющей кремния в ней.

В работе Компанеца и соавторов [114] изучалось влияние на кинетику быстрой релаксации возбужденных состояний в кремниевых квантовых точках окисления их поверхности в дейтерированном и протонированном диметилсульфоксиде. Обработка кремниевых квантовых точек диаметром $2.5 \mathrm{~nm}$ производилась плавиковой кислотой в обычной и дейтерированной воде с последующим окислением атмосферным кислородом в протонированном или дейтерированном диметилсульфоксиде. В образце, обработанном дейтерированными соединениями, появилась красная люминесценция с максимумом около $810 \mathrm{~nm}$, в то время как в аналогичных образцах, обработанных протонированными аналогами, PL практически отсутствовала. Появление красной люминесценции авторы объяснили пассивацией кремниевого ядра кислородом и появлением автолокализованного экситона и быстрой релаксации за 0.5 ps в это состояние. Рассматривая причину существенного ускорения окисления кремниевых квантовых точек в дейтерированной среде по сравнению с протонированной, следует 
учесть существенно большую длительность жизни возбужденного синглетного кислорода в дейтерированных растворителях (см. параграф 8.3.3 монографии [17] и работу [115]). Участие синглетного кислорода в фотоокислении кремниевых квантовых точек, приводящее к появлению их PL, весьма вероятно.

В работе [116] исследовались кремниевые квантовые точки, пассивированные карбазолом, что значительно повысило их квантовые выходы PL за счет образования поверхностных уровней, на которые передается энергия, поглощенная в ядре точки. Влияние облучения окисленных кремниевых квантовых точек размером 3 и $5 \mathrm{~nm}$, пассивированных додеканом, изучалось в работе Янга и соавторов [117]. Было установлено, что при облучении точек, люминесцирующих в красной области спектра, в присутствии восстановительной атмосферы в люминесценции кроме микросекундного компонента появляется также свечение наносекундной длительности.

\section{Квантовые точки на основе прямозонных полупроводников}

Среди громадного количества работ, посвященных исследованиям PL квантовых точек на основе прямозонных полупроводников, особый интерес представляют работы о влиянии на их выходы и времена затухания свечения изменения частот колебаний окружения квантовой точки путем дейтерирования растворителя или перехода от водородсодержащих растворителей к растворителям, не содержащим легких атомов. Константа скорости безызлучательного перехода между двумя электронными уровнями за счет взаимодействия с колебаниями (молекулы, квантовой точки или окружающего растворителя) в соответствии с индуктивнорезонансной теорией пропорциональна следующим параметрам: 1) интегралу перекрытия нормированного на единичную площадь спектра излучения при электронном переходе с нормированным спектром колебательного поглощения, 2) константам скоростей электрических дипольных переходов между рассматриваемыми уровнями и находящихся в резонансе с ними полос колебательного поглощения, 3) обратно пропорциональна шестой степени расстояния $(R)$ между центрами электронного перехода и колебательного поглощения. В случае нескольких колебательных центров, взаимодействующих с излучающим, необходимо суммировать вклады каждого. Если это сплошная среда, например растворитель, то необходимо интегрировать по всему окружающему объему, что приводит к обратно пропорциональной кубической зависимости $\left(R^{-3}\right)$ вероятности тушения от расстояния до сплошного тушителя, например растворителя $[17,19,20]$.

Первой работой, посвященной влиянию замены растворителя на длительность люминесценции квантовых точек, была работа Ахарони и соавторов [118]. Были изучены квантовые точки InAs/CdSe/ZnSe, спектр люминесценции которых расположен около $9160 \mathrm{~cm}^{-1}$, проводилось сравнение длительности свечения люминесценции квантовых точек, растворенных в трифтортрихлорэтане и толуоле. Длительность свечения в первом растворителе приблизительно в два раза больше, чем во втором (табл. 5). Авторы исследовали зависимость времени затухания люминесценции от длины волны регистрации в обоих растворителях и установили, что наибольшее различие в длительностях совпадает по положению с максимумом обертонной ИК полосы толуола. Это свидетельствует о роли безызлучательного переноса энергии от полупроводниковой точки к окружающему растворителю и объясняет причину уменьшения времени затухания люминесценции в толуоле по сравнению с растворителем $\mathrm{C}_{2} \mathrm{~F}_{3} \mathrm{Cl}_{3}$. При оценках влияния молекул толуола на константу скорости безызлучательного перехода $\left(k_{\mathrm{nr}}\right)$ авторы принимали во внимание только молекулы растворителя на поверхности квантовой точки, что приводило к зависимости $k_{\mathrm{nr}}$ от расстояния $R^{-4}$. В случае растворителя необходимо учитывать весь окружающий объем с тушащими колебаниями, что приводит к пропорциональности $k_{\mathrm{nr}} \sim R^{-3}$, где $R-$ радиус сферы вокруг точки, в которой отсутствует растворитель $[17,20]$.

В работе Вена и соавторов [119] было изучено влияние замены в качестве растворителя обычной воды на $\mathrm{D}_{2} \mathrm{O}$ на выход и время затухания PL квантовых точек $\mathrm{HgTe}$, излучающих в районе $9400 \mathrm{~cm}^{-1}$ (табл. 5). Хотя очевидно, что для объяснения наблюдаемого увеличения выхода флуоресценции в 4 раза при замене растворителя $\mathrm{H}_{2} \mathrm{O}$ на $\mathrm{D}_{2} \mathrm{O}$, а длительности люминесценции в 2 раза логичнее привлечь (как и при дейтерировании растворителей в окружении ионов лантанидов и переходных металлов [20] или при дейтерировании органических молекул $[14,19])$ процесс фёрстеровского электронноколебательного переноса энергии, в работе [119] предлагается другое объяснение наблюдаемому эффекту: через образование плотного спектра поляронов, вызываемого сильными взаимодействиями между состояниями ловушки и колебательными модами окружения. Мы считаем, что объяснение безызлучательных переходов переносом электронного возбуждения на колебания благодаря электрическим диполь-дипольным взаимодействиям (доказанное на громадном количестве различных объектов) более обосновано.

В то же время выходы PL квантовых точек HgTe по мере увеличения их размера и сдвига спектра все дальше в ИК область (табл. 5) падают достаточно сильно даже в растворе $\mathrm{CCl}_{4}[120]$, что, возможно, происходит из-за присутствия у квантовой точки лиганда - тиоглицерина. Такое падение хорошо согласуется с приблизительно экспоненциальным уменьшением интенсивности ИК поглощения колебания с увеличением номера обертона и, следовательно, экспоненциальным ростом интеграла перекрытия спектра излучения квантовой точки с полосами обертонного колебательного поглощения по мере продвижения к основной полосе. 
Таблица 5. Квантовые выходы и времена затухания люминесценции квантовых точек на основе прямозонных полупроводников

\begin{tabular}{|c|c|c|c|c|c|c|}
\hline $\begin{array}{l}\text { Квантовая точка, } \\
\text { лиганд, радиус, nm }\end{array}$ & Растворитель & $\begin{array}{l}\text { Частота макс. } \\
\mathrm{PL}, \mathrm{cm}^{-1}\end{array}$ & $\begin{array}{c}\text { Квантовый } \\
\text { выход PL }\end{array}$ & $\begin{array}{c}\text { Время затухания } \\
\text { PL, ns }\end{array}$ & $T, \mathrm{~K}$ & Литература \\
\hline InAs/CdSe/ZnSe 2.85 & $\mathrm{C}_{7} \mathrm{H}_{8}$ & $\sim 9160$ & 0.50 & 98 & RT & 118 \\
\hline InAs/CdSe/ZnSe 2.85 & $\mathrm{C}_{2} \mathrm{~F}_{3} \mathrm{Cl}_{3}$ & $\sim 9160$ & 0.60 & 202 & RT & 118 \\
\hline InAs/CdSe/ZnSe 2.85 & PVB & $\sim 9160$ & - & 45 & RT & 118 \\
\hline InAs/CdSe/ZnSe 2.85 & PFCB & $\sim 9160$ & - & 154 & RT & 118 \\
\hline InAs 2.15 & $\mathrm{C}_{7} \mathrm{H}_{8}$ & $\sim 9000$ & - & 3 & RT & 118 \\
\hline CdTe, 1.5 & $\mathrm{H}_{2} \mathrm{O}$ & 15625 & 0.77 & 24.4 & RT & 119 \\
\hline CdTe, 1.5 & $\mathrm{D}_{2} \mathrm{O}$ & 15625 & 0.86 & 26.3 & RT & 119 \\
\hline HgTe, 1.5 & $\mathrm{H}_{2} \mathrm{O}$ & 9390 & 0.05 & 49.5 & RT & 119 \\
\hline HgTe, 1.5 & $\mathrm{D}_{2} \mathrm{O}$ & 9452 & 0.20 & 89.27 & RT & 119 \\
\hline HgTe TG 1.5 & $\mathrm{CCl}_{4}$ & $\sim 9400$ & 0.40 & - & RT & 120 \\
\hline HgTe TG 3.0 & $\mathrm{CCl}_{4}$ & 4000 & 0.05 & - & RT & 120 \\
\hline HgTe TG 4.5 & $\mathrm{CCl}_{4}$ & 3330 & 0.02 & - & RT & 120 \\
\hline HgTe TG 6.0 & $\mathrm{CCl}_{4}$ & 2850 & 0.008 & - & RT & 120 \\
\hline HgTe DCT, 2.0 & $\mathrm{C}_{2} \mathrm{Cl}_{4}$ & 5000 & $\sim 0.08$ & $\tau_{1}=0.048 ; \tau_{2}=2$ & RT & 121,122 \\
\hline HgTe DCT, 2.7 & $\mathrm{C}_{2} \mathrm{Cl}_{4}$ & 3690 & $\sim 0.005$ & $\tau_{1}=0.045 ; \tau_{2}=0.380$ & RT & 121,122 \\
\hline HgTe DCT 7.25 & $\mathrm{C}_{2} \mathrm{Cl}_{4}$ & 2000 & $\sim 2 \cdot 10^{-4}$ & - & RT & 122 \\
\hline PbS OA 1.0 & $\mathrm{C}_{2} \mathrm{H}_{4} \mathrm{Cl}_{2}$ & 10500 & 0.60 & - & RT & 123 \\
\hline $\mathrm{PbS} \mathrm{OA}$ & $\mathrm{C}_{2} \mathrm{H}_{4} \mathrm{Cl}_{2}$ & 8500 & 0.20 & - & RT & 123 \\
\hline $\mathrm{PbS} \mathrm{OA}$ & $\mathrm{C}_{2} \mathrm{H}_{4} \mathrm{Cl}_{2}$ & 7800 & 0.37 & - & RT & 123 \\
\hline $\mathrm{PbS}$ OA & $\mathrm{C}_{2} \mathrm{H}_{4} \mathrm{Cl}_{2}$ & 6700 & 0.15 & - & RT & 123 \\
\hline PbS OA 5.0 & $\mathrm{C}_{2} \mathrm{H}_{4} \mathrm{Cl}_{2}$ & 5250 & 0.04 & - & RT & 123 \\
\hline $\mathrm{PbS} 1.5$ & $\mathrm{CCl}_{4}$ & 11350 & - & 2700 & RT & 127,128 \\
\hline $\mathrm{PbS} 2.0$ & $\mathrm{CCl}_{4}$ & 9060 & - & 1800 & RT & 127,128 \\
\hline $\mathrm{PbS} 3.25$ & $\mathrm{CCl}_{4}$ & 6800 & - & 800 & RT & 127,128 \\
\hline $\mathrm{PbS}$ & $\mathrm{C}_{6} \mathrm{H}_{14}$ & 11300 & $0.70^{1)}$ & & RT & 129 \\
\hline $\mathrm{PbS}$ & $\mathrm{C}_{6} \mathrm{H}_{14}$ & 11300 & $0.40^{2)}$ & & RT & 129 \\
\hline PbS-OA 1.2 & $\mathrm{C}_{7} \mathrm{H}_{8}$ & 10525 & $0.3-0.65$ & $\tau_{1}=50-200, \tau_{2}=400-1200$ & RT & 130 \\
\hline PbS-OA 1.65 & $\mathrm{C}_{7} \mathrm{H}_{8}$ & 9090 & $0.2-0.5$ & - & RT & 130 \\
\hline PbSe OA 1.0 & $\mathrm{C}_{2} \mathrm{H}_{4} \mathrm{Cl}_{2}$ & 10080 & 0.50 & - & RT & 123 \\
\hline $\mathrm{PbSe} \mathrm{OA}$ & $\mathrm{C}_{2} \mathrm{H}_{4} \mathrm{Cl}_{2}$ & 8870 & 0.24 & - & RT & 123 \\
\hline $\mathrm{PbSe} \mathrm{OA}$ & $\mathrm{C}_{2} \mathrm{H}_{4} \mathrm{Cl}_{2}$ & 7900 & 0.41 & - & RT & 123 \\
\hline $\mathrm{PbSe} \mathrm{OA}$ & $\mathrm{C}_{2} \mathrm{H}_{4} \mathrm{Cl}_{2}$ & 7260 & 0.20 & - & RT & 123 \\
\hline PbSe OA 5.0 & $\mathrm{C}_{2} \mathrm{H}_{4} \mathrm{Cl}_{2}$ & 5650 & 0.05 & - & RT & 123 \\
\hline PbSe 1.5 & $\mathrm{C}_{2} \mathrm{Cl}_{4}$ & 8330 & 0.81 & 250 & RT & 124 \\
\hline $\mathrm{PbSe} 4.0$ & $\mathrm{C}_{2} \mathrm{Cl}_{4}$ & 5260 & 0.12 & $>360$ & RT & 124 \\
\hline $\mathrm{PbSe}$ & $\mathrm{C}_{2} \mathrm{Cl}_{4}$ & 5800 & 0.20 & 200 & RT & 125 \\
\hline PbSe 2.9 & $\mathrm{CCl}_{3} \mathrm{H}$ & 6453 & 0.85 & 880 & RT & 126 \\
\hline $\mathrm{CdSe} / \mathrm{CdS} 3 \mathrm{ML}$ & $\mathrm{C}_{7} \mathrm{H}_{8}$ & 17790 & 0.73 & - & RT & 131 \\
\hline $\mathrm{CdSe} / \mathrm{ZnS} 3 \mathrm{ML}$ & $\mathrm{C}_{7} \mathrm{H}_{8}$ & $\sim 18000$ & 0.42 & - & RT & 131 \\
\hline CdSe ODA & $\mathrm{CCl}_{3} \mathrm{H}$ & 16700 & 0.3 & - & RT & 132 \\
\hline $\mathrm{CdSe} / \mathrm{CdS} / \mathrm{ZnCdS} / \mathrm{ZnS}$ ODA & $\mathrm{CCl}_{3} \mathrm{H}$ & 16330 & 0.7 & - & RT & 132 \\
\hline CdSe MPA & $\mathrm{H}_{2} \mathrm{O}$ & $\sim 17000$ & $<0.01$ & - & RT & 132 \\
\hline $\mathrm{CdSe} / \mathrm{CdS} / \mathrm{ZnCdS} / \mathrm{ZnS}$ MPA & $\mathrm{H}_{2} \mathrm{O}$ & $\sim 17000$ & 0.48 & - & RT & 132 \\
\hline $\mathrm{CdSe} / \mathrm{CdS} 1.65$ & $\mathrm{C}_{7} \mathrm{H}_{8}$ & 17850 & 0.77 & $\tau_{1}=5 ; \tau_{2}=18$ & RT & 133 \\
\hline $\mathrm{CdSe} / \mathrm{CdZnS} 1.52$ & $\mathrm{C}_{7} \mathrm{H}_{8}$ & 19000 & 0.76 & $\tau_{1}=4 ; \tau_{2}=17$ & RT & 133 \\
\hline CdSe-1.85 & $\mathrm{CCl}_{3} \mathrm{H}$ & 17000 & 0.05 & - & RT & 136 \\
\hline $\mathrm{CdSe} / \mathrm{ZnS} 1.85$ & $\mathrm{CCl}_{3} \mathrm{H}$ & 17000 & 0.50 & - & RT & 136 \\
\hline $\mathrm{CuInS}_{2} 1.5$ & $\mathrm{C}_{7} \mathrm{H}_{8}$ & 13550 & 0.22 & 300 & RT & 137 \\
\hline $\mathrm{CuInS}_{2} / \mathrm{CdS} 1.9$ & $\mathrm{C}_{7} \mathrm{H}_{8}$ & 13310 & 0.87 & 140 & RT & 138 \\
\hline $\mathrm{CuIn}_{2.3} \mathrm{Se}_{4} 1.7$ & TOP;OA & 10670 & $<0.25$ & - & RT & 140 \\
\hline $\mathrm{AgInS}_{2} 1.25 \mathrm{DCT}$ & $\mathrm{C}_{6} \mathrm{H}_{14}$ & $\sim 13700$ & 0.63 & 780 & RT & 139 \\
\hline $\mathrm{AgInS}_{2} 2.15 \mathrm{DCT}$ & $\mathrm{C}_{6} \mathrm{H}_{14}$ & $\sim 12900$ & 0.36 & 980 & RT & 139 \\
\hline
\end{tabular}

Примечание. 3ML - три монослоя оболочки ядра, $\mathrm{C}_{7} \mathrm{H}_{8}$ - толуол (toluene), ODA - октадециламин (octadecylamine), MPA - 3-меркаптопропионовая кислота (3-mercaptopropionic acid), TG - тиоглицерин (thioglycerol), DCT - 1-додекантиол (1-dodecanethiol), $\mathrm{C}_{2} \mathrm{~F}_{3} \mathrm{Cl}_{3}$ - трифтортрихлорэтан (trifluorotrichloroethane), PVB - поли(винилбутираль-винилалкоголь-винилацетат), poly(vinyl butyral-co-vinyl alkohol-co-vinyl acetate), PFCВ - полимер перфторциклобутана (perfluorocylobutane polymer), TOP — три-н-октилфосфин (tri-n-оctylphosphine), ОА — олеиновая кислота (oleic acid), PEDA — перфтортетрадекановая кислота (perfluorotetradecanoic acid), PFMCH — перфтор-1,3-диметилциклогексан (реrfluoro-1,3dimethylcyclohexane). 
Подробные исследования квантовых точек $\mathrm{HgTe}$, люминесцирующих в ИК области, были проведены в группе Гюот-Сионнест $[121,122]$ (табл. 5). В указанных работах подтверждена точка зрения о тушении PL квантовых точек в результате безызлучательного переноса энергии на высокочастотные колебания лигандов. Однако при теоретических оценках вероятности тушения (в отличие от нашего подхода в индуктивно-резонансной теории безызлучательных переходов для ионов лантанидов и переходных металлов) не используется теория Фёрстера, позволяющая такие оценки производить на основе данных о спектрах люминесценции точки и колебательного поглощения лигандов и окружения.

Симонин и соавторы [123] измерили квантовые выходы люминесценции серии квантовых точек $\mathrm{PbS}$ и $\mathrm{PbSe}$, люминесцирующих в области от 900 до $2000 \mathrm{~nm}$ $\left(11000-5000 \mathrm{~cm}^{-1}\right.$ ) (табл. 5). Выход, как это видно из данных табл. 5, высок (0.6-0.8) для квантовых точек $\mathrm{PbS}$ и $\mathrm{PbSe}$, которые излучают в области спектра короче $1 \mu \mathrm{m}$. Было подтверждено обнаруженное ранее падение выхода люминесценции квантовых точек при сдвиге спектра в ИК область. Причем в области 1050-1150 nm наблюдается отчетливая яма с провалом квантового выхода до 0.20 , подъем у $1250 \mathrm{~nm}$ до 0.35 и дальнейший спад выхода к $1900 \mathrm{~nm}$ до 0.04-0.05. Возможно, что сильное падение выхода PL квантовых точек $\mathrm{PbS}$ и $\mathrm{PbSe}$ в ИК области в работах Симонин и сотрудников [123] обусловлено наличием у точки в качестве лиганда олеиновой кислоты и использованием в качестве растворителя $\mathrm{C}_{2} \mathrm{H}_{4} \mathrm{Cl}_{2}$, ИК спектры которых содержит высокочастотные $\mathrm{C}-\mathrm{H}$-полосы и их обертоны, перекрывающиеся со спектрами PL квантовых точек $\mathrm{PbS}$ и $\mathrm{PbSe}$ и тушащие их по индуктивно-резонансному механизму безызлучательных переходов. Авторы [123] используют для оценки константы тушения формулу Фёрстера для диполь-дипольного переноса на поверхностный слой тушителя - олеиновой кислоты, но, как и в работе [118], не учитывают вклад всего объема окружающего точку растворителя. Предположение о заметном вкладе растворителя в дезактивацию квантовых точек PbSe подтверждают данные работ Дю с соавторами [124], которые работали с растворами точек $\mathrm{PbSe}$ в $\mathrm{CCl}_{4}$, и выход PL у них (для одинаковой области люминесценции в ИК диапазоне) был значительно больше по сравнению с данными Симонин и сотрудников [123], работавших с раствором $\mathrm{C}_{2} \mathrm{H}_{4} \mathrm{Cl}_{2}$ (табл. 5).

В работе Гуйот-Сионнест и Лию $[125,126]$ подтверждаются результаты работы [124] и при интерпретации данных указывается на диполь-дипольный механизм переноса энергии от квантовых точек $\mathrm{PbSe}$ на колебания лигандов в качестве причины тушения их флуоресценции. Мы согласны с их трактовкой, но считаем необходимым добавить к этому наличие тушения флуоресценции $\mathrm{PbSe}$ также за счет переноса на $\mathrm{C}-\mathrm{H}$ колебания растворителя, что указывает на относительно дальнодействующий характер процесса.
Исследуя времена затухания и спектры люминесценции квантовых точек $\mathrm{PbS}$ в ближней ИК области Баранов и соавторы $[127,128]$ пришли к выводу, что для непротиворечивого объяснения данных об изменениях стоксового сдвига спектров люминесценции и их длительности для квантовых точек разного размера необходимо рассматривать участие в процессе метастабильного „темного“ состояния, расположенного ниже излучающего уровня полосы проводимости, ранее уже не раз привлекаемого при рассмотрении схемы уровней квантовых точек [129]. Фактически получается аналог схемы Яблонского-Льюиса-Теренина для сложных органических молекул, включающей нижнее синглетное возбужденное флуоресцентное $S_{1}$-состояние и нижнее триплетное $T_{1}$, переход с которого в основное синглетное состояния $S_{0}$ запрещен. Позднее в работе 2014 г. авторы $[128]$ в схему уровней квантовых точек $\mathrm{PbS}$ диаметром 3.2-6.0 nm добавили расположенное ниже на $0.228-0.046 \mathrm{eV}$ излучающее состояние, связанное с поверхностными ловушками на квантовой точке.

В работах Ферни и соавторов [129] было установлено, что выход PL квантовых точек $\mathrm{PbS}$ зависит от того, в какой области спектра производится возбуждение. Максимальный выход 0.70 наблюдался при возбуждении в длинноволновой полосе поглощения и уменьшался до 0.40 при переходе к возбуждению в более коротковолновой области. В работе Гребена и соавторов [130], подробно изучавших PL квантовых точек $\mathrm{PbS}$, излучающих в ближней ИК области, также установили сильную ее зависимость от длины волны возбуждающего света и концентрации точек в растворе. При переходе от возбуждения на краю полосы поглощения квантовой точки в область спектра $6000-8000 \mathrm{~cm}^{-1}$, смещенную к более коротким длинам волн, наблюдается уменьшение квантового выхода приблизительно в полтора раза. Таким образом, в отличие от сложных органических молекул в конденсированной фазе закон Вавилова - правило Каша для растворов квантовых точек в большинстве случаев не соблюдается. Аналогичный вывод был сделан в работе Хои и соавторов [131], исследовавших квантовые точки CdSe и $\mathrm{CdSe} / \mathrm{ZnS}$. Наоборот, в работе Тонти и соавторов [132], работавших с аналогичными объектами, пришли к выводу, что небольшие отклонения спектра возбуждения PL квантовых точек от их спектра поглощения являются следствием рассеяния света на агрегатах квантовых точек.

В работах $[133,134]$ изучено влияние на квантовые выходы PL и фотостабильность квантовых точек из $\mathrm{CdSe}$ покрытия их оболочками из $\mathrm{CdS}$ или $\mathrm{ZnS}$. Шен и соавторы [135] изучали тушение PL квантовых точек $\mathrm{CdSe} / \mathrm{CdS}$ и $\mathrm{CdSe} / \mathrm{CdZnS}$, стабилизированных органическими лигандами, при очистке квантовых точек, приводящей к удалению слабо связанных лигандов, и восстановление PL при обратном присоединении к квантовым точкам некоторых из них. В работе Граболлэ и соавторов [136] наблюдалось десятикратное увеличение выхода флуорес- 
ценции точек CdSe при создании вокруг ядра оболочки из $\mathrm{ZnS}$ (табл. 5).

В табл. 5 приведены данные из работ Гамелина и сотрудников [137,138] о квантовых выходах, временах затухания и влиянии магнитного поля на PL квантовых точек $\mathrm{CuInS}_{2}$, о зависимости указанных величин от температуры, а также о процессах мигания PL отдельной точки. Авторы пришли к заключению о возможности объяснения наблюдаемых фактов с помощью схемы нижних возбужденных уровней $S_{1}, T_{1}$ и $S_{0}$, аналогичной известной схеме трех уровней Яблонского-ТеренинаЛьюиса для сложных органических молекул. Правда, энергетический зазор между $S_{1}$ - и $T_{1}$-уровнями составляет всего около $1.0 \mathrm{meV}$, а различие констант скоростей излучения с возбужденных синглетного и триплетного уровней на основное немного больше одного порядка. Квантовые точки состава $\operatorname{Ag}_{x} \operatorname{In}_{y} \mathrm{~S}_{z}$ изучались также в работе [139] (табл. 5).

Важным подтверждением наличия безызлучательного фёрстеровского переноса энергии от квантовых точек на чисто колебательные уровни лигандов или растворителя, приводящем к безызлучательным переходам и тушению фотолюминесценции в квантовых точках, послужило также проведение в работах Бодунова с соавторами $[141,142]$ изучение кинетики неэкспоненциального затухания PL квантовых точек $\mathrm{CdSe} / \mathrm{ZnS}$ и теоретический анализ растянутых экспоненциальных (stretched exponential) функций, описывающих этот процесс.

\section{Процессы релаксации в квантовых точках на основе прямозонных полупроводников}

В предыдущем разделе были рассмотрены выходы и длительности свечения при переходах, соответствующих переходу из зоны проводимости в валентную зону. В настоящем разделе мы остановимся на данных о скоростях процессов, происходящих в полупроводниковых квантовых точках между различными электронными уровнями внутри зоны проводимости и валентной зоны. Схема электронных уровней полупроводниковых квантовых точек, принятая в современной литературе, изображена на рис. 2. Хотя существование темного, возможно „триплетного“, уровня признается большинством авторов, но на приводимых схемах уровней они изображаются редко.

В 1998-1999 гг. Климов и сотрудники $[143,144]$ провели исследования кинетики затухания поглощения после импульсного возбуждения электронного состояния $1 P(\mathrm{e})$ в полосе проводимости коллоидных квантовых точек CdSe радиусом от 1.17 до $4.05 \mathrm{~nm}$. Было установлено, что процесс релаксации из второго возбужденного состояния $1 P(\mathrm{e})$ в нижнее состояние полосы проводимости $1 S(\mathrm{e})$ происходит за сотни фемтосекунд (табл. 6). Напрашивается аналогия с быстрой релаксацией электронной энергии из высоких возбужденных состояний сложных органических молекул

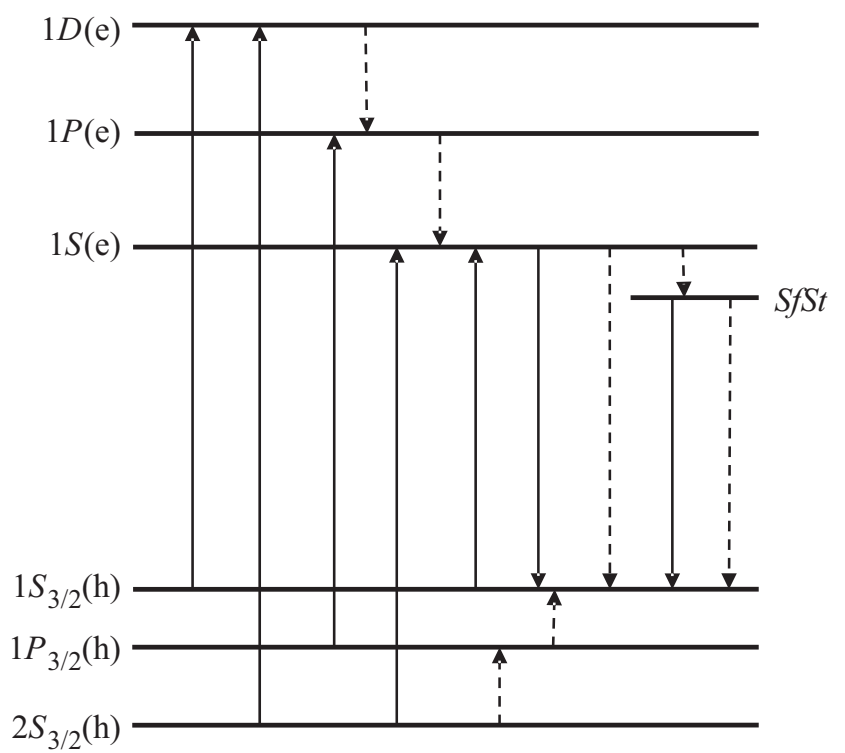

Рис. 2. Схема энергетических уровней и переходов между ними в квантовых точках, построенных из прямозонных полупроводников. В нижней части рисунка энергетические уровни дырок, располагающиеся внутри валентной зоны полупроводника, в верхней - то же для электронов внутри зоны проводимости. В правой части рисунка - поверхностный уровень - ловушка $S f S t$. Оже-процессы не рассматриваются, считая, что интенсивность возбуждения мала и вероятностью одновременного возбуждения двух электронов в зону проводимости одной квантовой точки можно пренебречь.

(закон Вавилова, правило Каша) [68]. При обсуждении механизма сверхбыстрой безызлучательной дезактивации между электронными уровнями внутри полосы авторы $[143,144]$ склоняются к оже-процессу и захвату поверхностными ловушками.

Изучение процессов релаксации между электронными уровнями внутри полосы проводимости квантовых точек $\mathrm{CdSe}$ с различными лигандами было проведено также Гуот-Сионнест с сотрудниками [145]. Была установлена зависимость скорости перехода между уровнями $1 P(\mathrm{e})$ и $1 S(\mathrm{e})$ от присоединенных к поверхности квантовой точки лигандов (табл. 6). Авторы исследования пришли к выводу, что вероятным процессом, приводящим к быстрому безызлучательному переходу внутри полосы, энергия которого соответствует средней ИК области спектра, где активны колебательные переходы с участием водорода, является безызлучательный дипольдипольный электронно-колебательный перенос энергии. Удивительно, что, рассматривая безызлучательный перенос энергии от электронно-возбужденных состояний квантовых точек на колебания за счет взаимодействия электрических диполей, авторы [145] не упоминают и не используют для теоретических оценок теорию Фёрстера $[10,11]$.

Как отмечают авторы [146], скорости внутренней конверсии (охлаждения) электрона и дырки в иссле- 
Таблица 6. Релаксация внутри полос квантовых точек на основе прямозонных полупроводников

\begin{tabular}{l|c|c|c|c|c|c|c}
\hline Квантовая точка & Радиус $R, \mathrm{~nm}$ & Растворитель & $\begin{array}{c}\text { Энергетический } \\
\text { зазор, } \mathrm{cm}^{-1}\end{array}$ & Переход & Время, fs & $T, \mathrm{~K}$ & Литература \\
\hline $\mathrm{CdSe}$ & 2.0 & $\mathrm{C}_{6} \mathrm{H}_{14}$ & $\sim 2200$ & $1 P(\mathrm{e})-1 S(\mathrm{e})$ & 300 & $\mathrm{RT}$ & 143 \\
$\mathrm{CdSe}$ & 4.2 & $\mathrm{C}_{6} \mathrm{H}_{14}$ & $\sim 2200$ & $1 P(\mathrm{e})-1 S(\mathrm{e})$ & 400 & $\mathrm{RT}$ & 143 \\
$\mathrm{CdSe}$ & 3.4 & glass & $\sim 2200$ & $1 P(\mathrm{e})-1 S(\mathrm{e})$ & 280 & $\mathrm{RT}$ & 143 \\
$\mathrm{CdSe}$ & 5.6 & glass & $\sim 2200$ & $1 P(\mathrm{e})-1 S(\mathrm{e})$ & 900 & $\mathrm{RT}$ & 143 \\
$\mathrm{CdSe}-$ TOPO & 1.17 & $\mathrm{C}_{6} \mathrm{H}_{14}$ & $\sim 2200$ & $1 P(\mathrm{e})-1 S(\mathrm{e})$ & 100 & $\mathrm{RT}$ & 144 \\
$\mathrm{CdSe}-$ TOPO & 1.73 & $\mathrm{C}_{6} \mathrm{H}_{14}$ & $\sim 2200$ & $1 P(\mathrm{e})-1 S(\mathrm{e})$ & 120 & $\mathrm{RT}$ & 144 \\
CdSe-TOPO & 2.33 & $\mathrm{C}_{6} \mathrm{H}_{14}$ & $\sim 2200$ & $1 P(\mathrm{e})-1 S(\mathrm{e})$ & 250 & $\mathrm{RT}$ & 144 \\
CdSe-TOPO & 2.77 & $\mathrm{C}_{6} \mathrm{H}_{14}$ & $\sim 2200$ & $1 P(\mathrm{e})-1 S(\mathrm{e})$ & 390 & $\mathrm{RT}$ & 144 \\
CdSe-TOPO & 4.05 & $\mathrm{C}_{6} \mathrm{H}_{14}$ & $\sim 2200$ & $1 P(\mathrm{e})-1 S(\mathrm{e})$ & 530 & $\mathrm{RT}$ & 144 \\
CdSe-TDPA & 2.5 & $\mathrm{C}_{2} \mathrm{Cl}_{4}$ & $\sim 2200$ & $1 P(\mathrm{e})-1 S(\mathrm{e})$ & $6 \cdot 10^{3}$ & $\mathrm{RT}$ & 144 \\
CdSe-OA & 2.5 & $\mathrm{C}_{2} \mathrm{Cl}_{4}$ & $\sim 2200$ & $1 P(\mathrm{e})-1 S(\mathrm{e})$ & $8 \cdot 10^{3}$ & $\mathrm{RT}$ & 145 \\
CdSe-OLA & 2.5 & $\mathrm{C}_{2} \mathrm{Cl}_{4}$ & $\sim 2200$ & $1 P(\mathrm{e})-1 S(\mathrm{e})$ & $12 \cdot 10^{3}$ & $\mathrm{RT}$ & 145 \\
CdSe-DDT & 2.5 & $\mathrm{C}_{2} \mathrm{Cl}_{4}$ & $\sim 2200$ & $1 P(\mathrm{e})-1 S(\mathrm{e})$ & $18 \cdot 10^{3}$ & $\mathrm{RT}$ & 145 \\
CdSe-ODA & 2.8 & $\mathrm{C}_{7} \mathrm{H}_{8}$ & $\sim 2500$ & $1 P(\mathrm{e})-1 S(\mathrm{e})$ & 200 & $\mathrm{RT}$ & 146 \\
CdSe-ODA & 2.8 & $\mathrm{C}_{7} \mathrm{H}_{8}$ & $\sim 4000$ & $2 S_{3 / 2}(\mathrm{~h})-1 S_{3 / 2}(\mathrm{~h})$ & 400 & $\mathrm{RT}$ & 146 \\
CdSe-MPA & 2.8 & $\mathrm{C}_{7} \mathrm{H}_{8}$ & $\sim 2500$ & $1 P(\mathrm{e})-1 S(\mathrm{e})$ & 200 & $\mathrm{RT}$ & 146 \\
CdSe-MPA & 2.8 & $\mathrm{C}_{7} \mathrm{H}_{8}$ & $\sim 4000$ & $2 S_{3 / 2}(\mathrm{~h})-1 S_{3 / 2}(\mathrm{~h})$ & 240 & $\mathrm{RT}$ & 146
\end{tabular}

Примечание. $\mathrm{C}_{6} \mathrm{H}_{14}$ - гексан (heхаne), ТОРО - три-н-октилфосфиноксид (tri-n-octylphosphine охіde), TDPA — тетрадецилфосфоновая кислота (tetradecylphosphonic acid), $\mathrm{C}_{2} \mathrm{Cl}_{4}$ - тетрахлорэтилен (tetrachloroethylene), OA - олеиновая кислота (oleic acid), OLA - аминалат (oleylamine), DDT - додекантиол (dodecanethiol), ODA — октадециламин (octadecylamine), MPA - 3-меркаптопропионовая кислота (3-mеrсарорropionic acid), $\mathrm{C}_{7} \mathrm{H}_{8}$ - толуол (toluene).

дуемых квантовых точках CdSe-ODA и CdSe-MPA не зависят от используемых лигандов. При рассмотрении данных табл. 6 о скорости релаксации в квантовых точках CdSe обращает на себя внимание, что для точек приблизительно одинаковых радиусов $(\sim 2.5 \mathrm{~nm})$ наблюдается большое различие в скорости релаксации со второго возбужденного уровня электрона $1 P(\mathrm{e})$ на первый возбужденный уровень $1 S(\mathrm{e})$. По данным Климова и сотрудников [144] время затухания уровня $1 P(\mathrm{e})$ составляет $0.25-0.39 \mathrm{ps,} \mathrm{по} \mathrm{данным} \mathrm{работы} \mathrm{[146]} \mathrm{-}$ $0.2 \mathrm{ps}$, в то время как в работе Guyot-Sionnest [144] для таких же точек времена релаксации на полтора порядка длиннее - 6.0-18.0 ps. По нашему мнению, данное различие обусловлено использованием в первых двух работах в качестве растворителей гексана и толуола, включающих протоны и, следовательно, высокочастотные колебания с высокой ангармоничностью, в то время как в работе [145] в качестве растворителя применялся тетрахлорэтилен, у которого отсутствуют высокочастотные колебания такой же интенсивности. Таким образом, весьма вероятно, что процесс релаксации между уровнями $1 P(\mathrm{e})$ и $1 S(\mathrm{e})$ осуществляется по механизму диполь-дипольного переноса энергии электронного возбуждения на колебания, в том числе на колебания растворителя.

\section{Выводы}

Подводя итог сделанному обзору работ по PL квантовых точек в конденсированной фазе, следует обратить внимание на большое сходство фотопроцессов в них с таковыми, осуществляющимися в сложных органических молекулах. Так же как и в сложных органических молекулах, в квантовых точках существует система синглетных и триплетных уровней. Одновременно следует указать на имеющие место различия, например во многих случаях в квантовых точках не соблюдается закон Вавилова-правило Каша о независимости квантового выхода PL от длины волны возбуждающего света. Кроме того, при рассмотрении фотопроцессов в квантовых точках различного типа необходимо учитывать возможность диффузии экситонов и захват их поверхностными ловушками, часто выступающими в качестве центров излучения PL.

Существенным результатом рассмотрения безызлучательных переходов в квантовых точках различного типа явились доказательства применимости к объяснению их закономерностей индуктивно-резонансной теории безызлучательных переходов между электронными уровнями, основанной на представлениях о взаимодействии электрического дипольного электронного перехода с электрическими дипольными переходами окружающей системы колебательных уровней. Такой подход позволяет дать удовлетворительное объяснение влиянию растворителей на квантовые выходы и времена затухания PL различных квантовых точек, излучающих в далекой красной и ИК областях спектра (табл. 5). Кроме того, с этих позиций понятно также влияние растворителя на быстрые процессы релаксации при электронных переходах внутри зоны проводимости и валентной зоны (табл. 6). 


\section{Список литературы}

[1] Гапоненко С.В., Розанов Н.Н., Ивченко Е.Л., Федоров А.В., Баранов А.В., Бонч-Бруевич А.М., Вартанян Т.А., Пржсибельский С.Г. Оптика наноструктур. / Под ред. Федорова А.В. СПб.: Недра, 2005. 326 с.

[2] Jing L., Kershaw St.V., Li Y., Huang X., Li Y., Rogach A.L., Gao M. // Chem. Rev. 2016. V. 116. P. 10623-10730.

[3] Harris R.D., Homan S.B., Kodaimati M., He Ch., Nepomnyashchii A.B., Swenson N.K., Lian Sh., Calzada L., Weiss E.A. // Chem. Rev. 2016. V. 116. P. 12865-12919.

[4] Kilina S.V., Tamukong P.K., Kilin D.S. // Accounts Chem. Research. 2016. V. 49. P. 2127-2135.

[5] Pietryga I.M., Park J-Sh., Lim J., Fidler A.F., Bae W.K., Brovelli S., Klimov V.I. // Chem. Rev. 2016. V. 116. P. 10513-10622.

[6] Zhu Sh., Song Y., Zhao X., Shao J., Zhang J., Yang B. // Nano Research. 2016. V. 8. P. 355-381.

[7] Lim S.Y., Shen W., Gao Z. // Chem. Soc. Rev. 2015. V. 44. P. 362-381.

[8] Ищенко А.А., Фетисов Г.В., Асланов Л.А. Нанокремний: свойства, получение, применение, методы исследования и контроля. М.: Физматлит, 2012. 648 с.

[9] Ischenko A.A., Fetisov G.V., Aslanov L.A. Nanosilicon: Properties, Synthesis, Applications, Methods of Analysis and Control. N.Y.: CRC Press. Teylar \& Francis Group, London: Boca Raton, 2015. 755 p.

[10] Förster Th. // Annalen der Physik. 1948. Bd. 437. S. 55-75.

[11] Förster Th. // Discus. Faraday Soc. 1959. N 27. P. 7-17.

[12] Свешникова Е.Б., Ермолаев В.Л. // Опт. и спектр. 1971. T. 30. C. $379-380$.

[13] Förster Th. // Chem. Phys. Lett. 1971. V. 12. P. 422-424.

[14] Ermolaev V.L., Sveshnikova E.B. // Chem. Phys. Lett. 1973. V. 23. P. 349-354.

[15] Бодунов Е.Н., Свешникова Е.Б. // Опт. и спектр. 1974. T. 36. C. $340-346$.

[16] Bodunov E.N. // Opt. Spectrosc. 1976. V. 40. P. 537-538.

[17] Ермолаев В.Л., Бодунов Е.Н., Свешникова Е.Б., Шахвердов T.A. Безызлучательный перенос энергии электронного возбуждения. Л.: Наука, 1977. Гл. 8.

[18] Ermolaev V.L., Sveshnikova E.B. // J. Luminesc. 1979. V. 20. P. 387-395.

[19] Ермолаев В.Л., Свешникова Е.Б., Бодунов Е.Н. // Усп. физ. наук. 1996. Т. 166. С. 279-302; Ermolaev V.L., Sveshnikova E.B., Bodunov E.N. // Phys.-Usp. 1996. V. 39. P. 261-282. An erratum for this article has been published in Phys.-Usp. 1997. V. 40. P. 335.

[20] Свешникова Е.Б., Ермолаев В.Л. // Опт. и спектр. 2011. T. 111. C. 38-54; Sveshnikova E.B., Ermolaev V.L. // Opt. Spectrosc. 2011. V. 111. P. 34-50.

[21] Vavilov S.I. // Phil. Mag. 1922. V. 43. P. 307-320.

[22] Kasha M. // Discus. Farad. Soc. 1950. V. 9. P. 14-19.

[23] Takeoka Sh., Fujii M., Hayashi Sh. // Phys. Rev. B. 2000. V. 62. P. $16820-16825$.

[24] Deng Y., Zhuo D., Chen X., Wang F., Song H., Shen D. // Chem. Commun. 2013. V. 49. P. 5751-5753.

[25] Li Q., Zhou M., Yang Q., Wu Q., Shi J., Gong A., Yand M. // Chemistry of Mater. 2016. V. 28. N 22. P. 8221-8227.

[26] Tan J., Zou R., Zhang J., Li W., Zhang L., Yue D. // Nanoscales. 2016. V. 8. P. 4742-4747.
[27] Sun Y.-P., Zhou B., Lin Y., Wang W., Shiral Fernando K.A., Pathak P., Meziane M.J., Harruff B.A., Wang X., Wang H., Luo P.G., Yang H., Kose M.E., Chen B., Veca L.M., Xie S.-Y. // J. Amer. Chem. Soc. 2006. V. 128. P. 7756-7757.

[28] Теренин А.Н. Фотоника молекул красителей и родственных органических соединений. Л.: Наука, 1967. 616 с.

[29] Турро Н. Молекулярная фотохимия. М.: Мир, 1967. 328 c.; Turro N.J. // Molecular Photochemistry. N.Y., Amsterdam: W.A. Benjamin. Inc., 1965.

[30] Калверт Джс., Питтс Джс. Фотохимия. М.: Мир, 671 с.; Calvert J.G., Pitts J.N. Photochemistry. N.Y., London, Sydney: J. Wiley \& Sons, 1966.

[31] Мак-Глинн С., Адзуми Т., Киносита М. Молекулярная спектроскопия триплетного состояния. М.: Мир, 1972. 448 c.; McGlynn S.P., Azumi T., Kinoshita M. Molecular Spectroscopy of the Triplet State. New Jersey: Prentice-Hall, Inc., 1969.

[32] Zhao L., Yu X., Zhang S., He X., Li L., Jia M., Chang M., Pan H., Chen J., Wang $W$., Xu J. // RSC Advanced. 2017. V. 7. P. 22684-22691.

[33] Anilkumar P., Wang X., Cao L., Sahu S., Liu J.-H., Wang P., Korch K., Tackett II K.N., Parenzan A., Sun Y.-P. // Nanoscale. 2011. V. 3. P. 2023-2027.

[34] Cao L., Yang Sh.-T., Wang X., Luo P.G., Liu J.-H., Sahu S., Liu Y., Sun Y.-P. // Theranostics. 2012. V. 2. P. 295-301.

[35] Yang Y., Cui J., Zheng M., Hu C., Tan S., Xiao Y., Yang Q., Liu Y. // Chem. Commun. 2012. V. 48. P. 380-382.

[36] Sahu S., Behera B., Maiti T.K., Mohapatra S. // Chem. Commun. 2012. V. 48. P. 8835-8837.

[37] Liang Q., Ma W., Shi Y., Li Z., Yang X. // Carbon. 2013. V. 60. P. 421-428.

[38] Li X., Zhang Sh., Kulinich S.A., Lu Y., Zang H. // Scientific Reports. 2014. V. 4. P. 4976.

[39] Li F., Liu Ch., Yang J., Wang Z., Liu W., Tian F. // RSC Advances. 2014. V. 4. P. 3201-3205.

[40] Feng X.T., Zhang F., Wang Y.L., Zhang Y., Yang Y.Z., Liu X.G. // Appl. Phys. Lett. 2015. V. 107. P. 213102.

[41] Nguyen V., Yan L., Si J., Hou X. // Optical Materials Express. 2016. V. 6. P. 312-320.

[42] Sun Sh., Zhang L., Jiang K., Wu A., Lin H. // Chem. Mater. 2016. V. 28. P. 8659-8668.

[43] Jiang Z.C., Lin T.N., Lin H.T., Talite M.J., Tzeng T.T., Hsu1 C.L., Chiu K.P., Lin C.A.J., Shen J.L., Yuan C.T. // Scientific Reports. 2016. V. 6. P. 19991.

[44] Kim T.H., White A.R., Sirdaarta J.P., Ji W., Cock I.E., John J.St., Boyd S.E., Brown Ch.L., Li Q. // ACS Appl. Mater. Interfaces. 2016. V. 8. P. 33102-33111.

[45] Ogi T., Iwasaki H., Aishima K., Iskandar F., Wang W.-N., Takimiya K., Okuyama K. // RSC Advances. 2014. V. 4. P. 55709-55715.

[46] Ogi T., Aishima K., Permatasari F.A., Iskandar F., Tanabe E., Okuyama K. // New J. Chem. 2016. V. 40. P. 5555-5561.

[47] Wang L., Yin Y., Jain A., Zhou S. // Langmuir. 2014. V. 30. P. $14270-14275$.

[48] Sk M.R., Chattopadhyay A. // RSC Advances. 2014. V. 4. P. 31994-31999.

[49] Zhu S., Meng Q., Wang L., Zhang J., Song Y., Jin H., Zhang K., Sun H., Wang H., Yang B. // Angew. Chem. Int. Ed. 2013. V. 52. P. 3953-3957.

[50] Wang F., Chen Y.-H., Lin Ch.-Y., Ma D.-G. // Chem. Commun. 2011. V. 47. P. 3502-3504. 
[51] Fan Y., Guo X., Zhang Y., Lv Y., Zhao J., Liu X. // ACS Appl. Mater. Interfaces. 2016. V. 8. P. 31863-31870.

[52] Li H., Shao F.-Q., Zou S.-Y., Yang Q.-J., Huang H., Feng J.-J., Wang A.-J. // Microchimica Acta. 2016. V. 183. P. 821-826.

[53] Li J., Jiao Y., Feng L., Zhong Y., Zuo G., Xie A., Dong W. // Microchim. Acta. 2017. V. 184. P. 2933-2940.

[54] Parvin N., Mandal T.K. // Microchimica Acta. 2017. V. 184. P. 1117-1125.

[55] Schneider J., Reckmeier C.J., Xiong Y., Von Seckendorff M., Sucha A.S., Kasak P., Rogach A.L. // J. Phys. Chem. C. 2017. V. 121. P. 2014-2022.

[56] Dong Y., Pang H., Yang H.B., Guo C., Shao J., Chi Y., Li C.M., Yu T. // Angew. Chem. Int. Ed. 2013. V. 52. P. 7800-7804.

[57] Kalytchuk S., Polakova K., Wang Y., Froning J.P., Cepe K., Rogach A.L. // ACS Nano. 2017. V. 11. P. 1432-1442.

[58] Yang M., Meng X., Li B., Ge Sh., Lu Y. // J. Nanoparticle Research. 2017. V. 19. P. 217-229.

[59] Xu Q., Pu P., Zhao J., Dong Ch., Gao Ch., Chen Y., Chen J., Liu Y., Zhou H.J. // Mater. Chem. A. 2015. V. 3. P. 542-546.

[60] Ding H., Yu S.-B., Wei J.-S., Xiong H.-M. // ACS Nano. 2016. V. 10. P. 484-491.

[61] Yuan F., Wang Z., Li X., Li Y., Tan Z., Fan L., Yang S. // Advanced Materials. 2017. V. 29. P. 1604436-1-6.

[62] Wang W., Wang B., Embrechts H., Damm C., Cadranel A., Strauss V., Distaso M., Hinterberger V., Guldi D.M., Peukert $W$. // RSC Advances. 2017. V. 7. P. 24771-24780.

[63] Mueller M.L., Yan X., McGuire J.A., Li L.-S. // Nano Lett. 2010. V. 10. P. 2679-2682.

[64] Yang P., Zhou L., Zhang Sh., Wan N., Pan W., Shen W. // J. Appl. Phys. 2014. V. 116. P. 244306.

[65] Deng X., Sun J., Yang S., Shen H., Zhou W., Lu J., Ding G., Wang Z. // Appl. Phys. Lett. 2015. V. 107. P. 241905.

[66] Wang Z., Yuan F., Li X., Li Y., Zhang H., Fan L., Yang Sh. // Advanced Materials. 2017. V. 27. P. 1702910.

[67] Zhao L., Yu X., Zhang S., He X., Li L., Jia M., Chang M., Pan H., Chen J., Wang W., Xu J. // RSC Advance. 2017. V. 7. P. 22684-22691.

[68] Tao S., Song Y., Zhu Sh., Shao J., Yang B. // Polymer. 2017. V. 116. P. $472-478$.

[69] Ermolaev V.L., Lubimtsev V.A. // Acta Phys. Polon. 1987. V. A71. P. 731-741.

[70] Ермолаев В.Л. // Успехи химии. 2001. Т. 70. № 6. С. 539; Ermolaev V.L. // Russ. Chem. Rev. 2001. V. 70. N 6. P. 471-490.

[71] Němec P., Preclíková J., Kromka A., Rezek B., Trojánek F., Maly P. // Appl. Phys. Lett. 2008. V. 93. P. 083102.

[72] Sui L., Jin W., Li S., Liu D., Jiang Y., Chen A., Liu H., Shi Y., Ding D., Jin M. // PhysChemChemPhys. 2016. V. 18. P. 3838-3845.

[73] Wang W., Wang B., Embrechts H., Damm C., Cadranel A., Strauss V., Distaso M., Hinterberger V., Guldi D.M., Peukert $W$. // RSC Advances. 2017. V. 7. P. 24771-24780.

[74] Wang L. Zhu Sh.-J., Wang H.-Y., Wang Y.-F., Hao Y.-W., Zhang J.-H., Chen Q.-D., Zhang Y.-L., Han W., Yang B., Sun H.-B. // Advanced Opt. Mater. 2013. V. 1. P. 264-271.

[75] Zhang Q., Luo $Y$. // High Power Laser Science and Engineering. 2016. V. 4. P. 1-10.

[76] Caham L.T. // Appl. Phys. Lett. 1990. V. 57. P. 1046-1048.

[77] Wilson W.L., Szajowski P.F., Brus L.E. // Science. 1993. V. 262. P. $1242-1244$.
[78] Littau K.A., Szajowwski P.F., Muller A.J., Kortan A.R., Brus L.E. // J. Phys. Chem. 1993. V. 97. P. 1224-1230.

[79] Mazzaro R., Romano F., Ceroni P. // Phys. Chem. Chem. Phys. 2017. V. 19. P. 26507-26526.

[80] Ledoux L., Gong J., Huisken F., Guillois O., Reynaud C. // Appl. Phys. Lett. 2002. V. 80. P. 4834-4836.

[81] Valenta J., Juhasz R., Linnros J. // J. Luminesc. 2002. V. 98. P. $15-22$.

[82] Jurbergs D., Rogojina E., Mangolini L., Kortshagen U. // Appl. Phys. Lett. 2006. V. 88. P. 233116-1-3.

[83] Mangolini L., Jurbergs D., Rogojina E., Korthagen U. // J. Luminesc. 2006. V. 121. P. 327-334.

[84] Walters R.J., Kalkman J., Polman A., Atwater H.A., deDood M.J.A. // Phys. Rev. B. 2006. V. 73. P. 132302-1-4.

[85] Pi X.D., Liptak R.W., Nowak J.D., Wells N.P., Carter C.B., Campbell S.A., Kortshagen U. // Nanothechnology. 2008. V. 19. P. 245603-1-5.

[86] Anthony R., Kortshagen U. // Phys. Rev. B. 2009. V. 80. P. 115407-1-6.

[87] Dohnavalova K., Kusova K., Pelant I. // Appl. Phys. Lett. 2009. V. 94. P. 211903-1-3.

[88] Xe Y., Su Y., Yang X., Kang Z., Xu T., Zhang R., Fan Ch., Lee Sh.-T. // J. Amer. Chem. Soc. 2009. V. 131. P. 4434-4438.

[89] Patrick K., Schmidt T., Bublitz S., Muhlig Chr., Paa W., Huisken F. // Appl. Phys. Lett. 2011. V. 98. P. 083111.

[90] Hannah D.C., Jang J., Podsiadlo P., Chan M.K.Y., Demortiere A., Gosztole D.J., Prakarenka V.B., Schatz G.C., Kortshagen U., Schallen R.D. // Nano Lett. 2012. V. 12. P. 4200-4205.

[91] Li Q., He Y., Chang J., Wang L., Chen H., Tan Y.-W., Wang H., Shao Z. // J. Amer. Chem. Soc. 2013. V. 135. P. 14924-14927.

[92] Tu Ch.-Ch., Hoo J.H., Bohringer K.F., Lin L.Y., Cao G. // Optics Express. 2014. V. 22. P. A276-A281.

[93] Yang L., Liu Y., Zhong Y.-L., Jiang X.-X., Song B., Ji X.-Y., Su Y.-Y., Liao L.-Sh., He Y. // Appl. Phys. Lett. 2015. V. 106. P. 173109.

[94] Valenta J., Greben M., Gutsch S., Hiller D., Zacharias M. // Appl. Phys. Lett. 2014. V. 105. P. 243107.

[95] Sangghalen F., Sychugov I., Yang Z., Veinot J.G.C., Linnros J. // ACS Nano. 2015. V. 9. P. 7097-7104.

[96] Valenta J., Greben M., Remes Z., Gratsch S., Hillen D., Zacharias M. // Appl. Phys. Lett. 2016. V. 108. P. 023102.

[97] Li Q., Luo T.-Y., Zhoi M., Abroshan H., Huang J., Kim H.J., Rosi N.L., Shao Z., Jin R. // ACS Nano. 2016. V. 10. P. 8385-8393.

[98] Brown S.L., Krishnan R., Elbaradei A., Sivaguru J., Sibi M.P., Hobbie E.K. // AIP Advances. 2017. V. 7. P. 055314

[99] Brown S.L., Miller J.B., Anthony R.J., Kortshagen U.R., Kryjevski A., Hobbie E.K. // ACS Nano. 2017. V. 11. P. 1597-1603.

[100] Greben M., Khoroshyy P., Liu X., Pi X., Valenta J. // J. Appl. Phys. 2017. V. 122. P. 034304.

[101] Kusová K., Hapala P., Valenta J., Jelínek P., Cibulka O., Ondic L., Pelant I. // Adv. Mater. Interfaces. 2014. V. 1. P. 1300042-1-9.

[102] Klimov V.I., Schwarz Ch.J,, McBranch D.W., White C.W. // Appl. Phys. Lett. 1998. V. 73. P. 2603-2605.

[103] Trojanek F., Neudert K., Maly P., Dohnalova K., Pelant I. // J. Appl. Phys. 2006. V. 99. P. 116108. 
[104] Lioudakis E., Othonos A., Nassiopoulou A.G. // Appl. Phys. Lett. 2007. V. 90. P. 171103.

[105] Sykora M., Mangolini L., Schaller R.D., Kortshagen U., Jurbergs D., Klimov V.I. // Phys. Rev. Lett. 2008. V. 100. P. 067401.

[106] Kuntermann V., Cimpean C., Brehm G., Sauer G., Kryschi C. // Phys. Rev. B. 2008. V. 77. P. 115343.

[107] Cimpean C., Groenewegen V., Kuntermann V., Sommer A., Kryschi C. // Laser \& Photon. Rev. 2009. V. 3. P. 138-145.

[108] Groenewegen V., Kuntermann V., Haarer D., Kunz M., Kryschi C. // J. Phys. Chem. C. 2010. V. 114. P. $11693-11698$.

[109] Atkins T.M., Thibert A., Larsen D.S., Dey S., Browning N.D., Kauzlarich S.M. // J. Amer. Chem. Soc. 2011. V. 133. P. 20664-20667.

[110] Sommer A., Cimpean C., Kunz M., Oelsner Ch., Kupka H.J., Kryschi C. // J. Phys. Chem. C. 2011. V. 115. P. 22781-22788.

[111] Hannah D.C., Yang J., Kramer N., Schatz G.C., Kortshagen U.R., Schaller R.D. // ACS Photonics. 2014. V. 1. P. 960-967.

[112] Kusová K., Ondič L., Pelant I. // ACS Photonics. 2015. V. 2. P. 454-455.

[113] Hannah D.C., Yang J., Kramer N., Schatz G.C., Kortshagen U.R., Schaller R.D. // ACS Photonics. 2015. V. 2. P. 456-458.

[114] Компанец В.О., Чекалин С.В., Дорофеев С.Г., Кононов Н.Н., Барзилович П.Ю., Ищенко А.А. // Квант. электрон. 2014. Т. 44. № 6. С. 552-555.

[115] Merkel P.B., Kearns D.R. // J. Amer. Chem. Soc. 1972. V. 94. P. 7244-7253.

[116] Wang L., Li Q., Wang H.-Y., Huang J.-C., Zhang R., Chen Q.-D., Xu H.-L., Han W., Shao Z.-Z., Sun H.-B. // Light: Science \& Applications. 2015. V. 4. P. 245.

[117] Yang Z., De los Reyes G.B., Titova L.V., Sychugov I., Dasog M., Linnros J., Hegmann F.A., Veinot J.G.C. // ACS Photonics. 2015. V. 2. P. 595-605.

[118] Aharoni A., Oron D., Banin U., Rabani E., Jortner J. // Phys. Rev. Lett. 2008. V. 100. P. 057404.

[119] Wen Q., Kershaw St.V., Kalytchuk S., Zhovtiuk O., Reckmeier C., Vasilevskiy M.I., Rogach A.L. // ACS Nano. 2016. V. 10. N 4. P. 4301-4311.

[120] Kovalenko M.V., Kaufmann E., Pachinger D., Roither J., Huber M, Stangl J., Hesser G., Schaffler F., Heiss W. // J. Amer. Chem. Soc. 2006. V. 128. P. 3516-3517.

[121] Keuleyan S., Lhuillier E., Guyot-Sionnest P. // J. Amer. Chem. Soc. 2011. V. 133. P. 16422-16424.

[122] Keuleyan S., Kohler J., Guyot-Sionnest P. // J. Phys. Chem. C. 2014. V. 118. P. 2749-2753.

[123] Simonin O.E., Jonson J.C., Luther J.M., Midgett A.G., Nozik A.J., Beard M.C. // J. Phys. Chem. Lett. 2010. V. 1. P. 2445-2450.

[124] Du H., Chen Ch., Krishnan R., Krauss T.D., Harbold J.M., Wise F.W., Thomas M.G., Sileox J. // Nano Lett. 2002. V. 2. N 11. P. 1321-1324.

[125] Liu H., Guyot-Sionnest P. // J. Phys. Chem. C. 2010. V. 114. P. $14860-14863$.

[126] Wehrenberg B.L., Wang C., Guyet-Sionnest P. // J. Phys. Chem. B. 2002. V. 106. P. 10634-10640.

[127] Литвин А.П., Парфенов П.С., Ушакова Е.И., Баранов А.В. // Научно-технич. вестник информ. технологий, механики и оптики. 2012. № 5. С. 32-38.
[128] Litvin A.P., Parfenov P.S., Ushakova E.V., Simões Gamboa A.L., Fedorov A.V., Baranov A.V. // J. Phys. Chem. C. 2014. V. 118. P. 20721.

[129] Fernee M.J., Thomsen E., Jensen P., Rubinsztein-Dunlor H. // Nanotechnology. 2006. V. 17. P. 956-962.

[130] Greben M., Fucikova A., Valenta J. // J. Appl. Phys. 2015. V. 117. P. 144306.

[131] Hoy J., Morrison P.J., Steinberg L.K., Buhro W.E., Loomis R.A. // J. Phys. Chem. Lett. 2013. V. 4. P. 2053-2060.

[132] Tonti D., van Mourik F., Chergui M. // Nano Lett. 2004. V. 4. N 12. P. 2483-2487.

[133] Mekis I., Talapin D.V., Kornowski A., Haase M., Weller H. // J. Phys. Chem. B. 2003. V. 107. N 30. P. 7454-7462.

[134] Xie R., Kolb U., Li J., Basche T., Mews A. // J. Amer. Chem. Soc. 2005. V. 127. P. 7480-7488.

[135] Shen Y., Tan R., Gee M.Y., Greytak A.B. // ACS Nano. 2015. V. 9. N 3. P. 3345-3359.

[136] Grabolle M., Ziegler J., Merkulov F., Nann T., ReschGenger U.// Ann. NY. Acad. Sci. 2008. V. 1130. P. 235-241.

[137] Knowles K.E., Nelson H.D., Kilburn T.B., Gamelin D.R. // J. Amer. Chem. Soc. 2015. V. 137. P. 13138-13147.

[138] Whitham P.J., Marchioro A., Knowles K.E., Kilburn T.B., Reid Ph.J., Gamelin D.R. // J. Phys. Chem. C. 2016. V. 120. P. 17136-17142.

[139] Harnanaka Y., Ozawa K., Kuzuya T. // J. Phys. Chem. C. 2014. V. 118. N 26. P. $14562-14568$.

[140] Allen P.M., Bawendi M.G. // J. Amer. Chem. Soc. 2008. V. 130. N 29. P. $9240-9241$.

141] Bodunov E.N., Danilov V.V., Panfutova A.S., Simões Gamboa A.L. // Ann. Phys. (Berlin). 2016. V. 528. N 3-4. P. 272-275.

[142] Bodunov E.N., Antonov Yu.A., Simões Gamboa A.L. // J. Chem. Phys. 2017. V. 146. P. 114102.

[143] Klimov V.I., McBranch D.W. // Phys. Rev. Lett. 1998. V. 80. N 18. P. 4028-4031.

[144] Klimov V.I., McBranch D.W., Leathardale C.A., Bawendi M.G. // Phys. Rev. B. 1999. V. 60. N 19. P. $13740-13749$.

[145] Guyot-Sionnest P., Wehrenberg B., Yu D. // J. Chem. Phys. 2005. V. 123. P. 074709.

[146] Schnitzenbaumer K,J., Labrador T., Dukovic G. // J. Phys. Chem. C. 2015. V. 119. P. 13314-13324. 